\title{
Child Height and Intergenerational Transmission of Health: Evidence from Ethnic Indians in England
}

\author{
Caterina Alacevich \\ Alessandro Tarozzi *
}

September 2016

\begin{abstract}
A large literature documents a widespread prevalence of small stature among Indian children as well as adults. We show that a height gap relative to a richer population such as whites in England also exists, although substantially reduced, among adult immigrants of Indian ethnicity in England. This is despite positive height selection into migration, demonstrated by ethnic Indian adults in England being on average 6-7 centimeters taller than in India. However, the difference between natives and ethnic Indians in England disappears among their younger sons and daughters, although it re-appears among adolescents. We estimate that, conditional on age, gender and parental height, ethnic Indian children of age 2 to 4 in England are 6 to $8 \%$ taller than in India. Such degree of catch up in one generation is remarkable, also because in England children of ethnic Indians have much smaller birthweight than whites, by about 0.4 kilograms on average.
\end{abstract}

JEL: F22, I15, O15

Keywords: Height, Indians, Intergenerational Transmission of health, Immigrants

*We are grateful to Macro International Inc., the UK Data Archive and the Inter-university Consortium for Political and Social Research for granting access to the data used in this article. We are also grateful for comments and suggestions from two anonymous reviewers, and to participants in seminars and workshops Bologna, Center for Economic and International Studies (CEIS, Tor Vergata), Essex, Queen Mary, Oxford (Nuffield College), 3rd PODER Summer School (Namur), Tilburg and Tor Vergata, and in particular to Lucia Corno, Francesco Fasani, Gianna Claudia Giannelli, Veronica Grembi, Chiara Monfardini, Franco Peracchi and Zahra Siddique. We gratefully acknowledge financial assistance from the "Policy Design and Evaluation Research in Developing Countries" Initial Training Network (PODER, funded under the Marie Curie Actions of the EU's Seventh Framework Programme, Contract Number: 608109), and from the Ministerio de Economía y Competitividad of the Spanish Government (grants ECO2015-71536ERC and ECO2015-69869-R). All errors and omissions are our own. Caterina Alacevich: Universitat Pompeu Fabra and Università Cattolica di Milano; caterina.alacevich@upf.edu; Alessandro Tarozzi: Universitat Pompeu Fabra, CRES and Barcelona GSE, Ramon Trias Fargas 25-27, 08005 Barcelona (Spain); alessandro.tarozzi@upf.edu. 


\section{Introduction}

In many countries, historical data show a strong positive correlation between improvements in living standards over time and increases in average height (Fogel 1994, Steckel 1995, Hatton and Bray 2010). ${ }^{1}$ Height, though strongly dependent on genetic factors, is also affected by individual circumstances such as medical history and nutrition. A large body of evidence shows that early-life conditions have a powerful and hard-to-reverse effect on adult height and that taller individuals enjoy on average better health and labor market outcomes (see Strauss and Thomas 1998, 2008 and Martorell et al. 1994 for reviews).

Despite impressive rates of economic growth in recent decades, India remains one of the worst performing countries worldwide in terms of height, among both children and adults (Deaton and Drèze 2009). For instance, according to estimates from the National Family Health Survey (NFHS), in 2005-06 about half of Indian children were stunted (that is, they had low height given age and gender), and about $40 \%$ were underweight. Child stunting and underweight are similarly widespread in Bangladesh and Pakistan, two neighboring countries. Indeed Ramalingaswami et al. (1996) coined the expression 'South Asian Enigma' in relation to rates of child malnutrition in these areas that are even higher than in several Sub-Saharan African countries, despite the latter doing worse in terms of child mortality and many other development indicators. The literature has recently proposed a number of likely contributing factors, highlighting the role of sanitation (Spears 2012), women's health and social status (Coffey et al. 2015, Coffey 2015a, Coffey 2015b), son preference (Jayachandran and Pande 2015) and eating habits (Bhalotra et al. 2010, Atkin 2013, 2016).

Several studies show that the widespread presence of small stature among Indian children relative to accepted international standards (also observed in well-off families) cannot be plausibly explained by genetic factors (Habicht et al. 1974, Agarwal et al. 1991 Bhandari et al. 2002, Coffey et al. 2013), although genetic-based explanations remain popular among some, see e.g. Panagariya (2013) who however ignores several of the likely contributing factors highlighted above. This paper contributes to the literature by looking at the inter-generational transmission of height. The extent of intergenerational transmission of health from mothers to children (including of growth performances) is well-documented e.g. in Bhalotra and Rawlings (2011, 2013), Currie and Moretti

\footnotetext{
${ }^{1}$ However, a number of researchers have cautioned against the use of average height as an indicator of economic development. For instance, Deaton (2007) shows that there is no clear cross-country correlation between the two indicators in developing countries.
} 
(2007) and Li and An (2015). Kim et al. (2015) use data from Indonesia and show that strong intergenerational correlations also exist between adult health or health changes and the health status and mortality of their parents.

We show that children of Indian ethnicity born and raised in England are substantially taller than children in India, even when we compare children whose parents have similar height. This is in line with the old hypothesis, first put forth by Boas (1912), that migration can play a role in conditioning human body characteristics, as a complement to the genetic and the inter-generational channel, see also Gravlee et al. (2003). This finding is also consistent with the possibility that convergence to international height standards may proceed, under appropriate conditions, much faster that what has been observed across generations in India (Deaton and Drèze, 2009).

This paper also contributes to the literature that studies selection into migration along health dimensions. We find evidence of strong positive selection into migration to England in terms of height with respect to the population of origin. Our result somewhat contrasts with the evidence of positive but weak selection on health among Mexican migrants in the United States, see Rubalcava et al. (2008), and aligns with the hypothesis that economic migration from geographically distant countries tends to disproportionately favor individuals positively selected from the sending country (Chiswick 1978, 1999, Chiquiar and Hanson 2005). Feliciano (2005) documented strong positive selectivity on education among immigrants in the United States.

We also show that the height of ethnic Indians who migrated to England in adulthood is on average substantially below that of natives in the destination country. This contrasts with what is known as the "healthy immigrant effect" well documented among several first-generation immigrant groups into developed countries such as the US, Canada, and Australia, where they often enjoy better health conditions relative to natives, see Farré (2016).

While ethnic Indian adults in England have a lower average height than native whites, we find no statistically significant difference among younger children, although a systematic gap does appear at later ages. This suggests that, at least in the crucial early childhood period, the gap with English natives disappeared within one generation, and is in line with previous findings by Tarozzi (2008) of catch-up with international standards. Tarozzi (2008) used data from the 1999 Health Survey of England and showed that children of Indian ethnicity who lived in England had anthropometric outcomes comparable to those in commonly used growth standards, and that the height of ethnic South Asians in the sample was negatively related to the amount of time spent outside England. Our results complement these findings by using a larger sample and, more importantly, by looking 
explicitly at the intergenerational link between parents and children's height. Proos et al. (1992) and Proos (2009) also documented fast catch up growth among Indian children adopted in Sweden, especially among the worst performers at the time of arrival. However, catch up was not complete, consistent with a large literature on the long-term consequences of poor health in early life. More recently, van den Berg et al. (2014) exploited variation among siblings in the age at the time of immigration into Sweden from poorer countries to show that individuals who migrated earlier in life were on average significantly taller. They also showed that adult height was particularly sensitive to the environment experienced around the puberty growth spurt.

The rest of the paper is organized as follows. Section 2 presents the data sources, two waves of the Health Survey for England (1998-99, and 2003-04), the third round of the National Family Health Survey of India (2005-06), and the second wave of the Indian Human Development Survey (2011-2012). Section 3 introduces the evidence on adult self-selection in terms of height and hemoglobin, comparing Indians in England with the general population of India. This section also presents the comparison with respect to the native population at destination, defined as individual of 'White' ethnicity in England. The analysis moves then to children, showing in section 4 that differences in height with respect to natives disappear in one generation among younger children, but not older children. Section 5 moves to the inter-generational framework and presents the results obtained from our main regressions, in which we control for parental height. In Section 5 we also look at birth weight of children born in England, and we show that despite the catch up in height observed among younger children of Indian ethnicity, there are substantial differences in birth weight, most likely due to the small stature of a large fraction of their mothers. Section 6 concludes and discusses a number of limitations of our findings.

\section{Data}

To estimate height performances in the Indian population, we use the third round of the National Family and Health Survey (NFHS-III), which is one of the largest and widely known household surveys in India. NFHS surveys are part of the Demographic and Health Surveys (DHS), which are nationally representative surveys conducted in many countries worldwide, and include information on demographic, nutrition, health and socio-economic characteristics of households, focusing mainly on mothers and children. At the time of writing data are available from three rounds of NFHS. ${ }^{2}$

\footnotetext{
${ }^{2}$ At the time of writing NFHS-4 has been completed by the micro data are not available for public use yet.
} 
Each one consists of an independent cross-section, and in this paper we use the most recent data set. It was conducted in 2005-06 and it includes a stratified and clustered sample of 109,041 households (see IIPS 2007, Appendix C, for additional details on the sample design). The survey was designed to generate a sample representative at the national, state and sector (rural vs. urban) level.

The data also recorded a number of biomarkers, including height and weight for children aged 0-5, women of fertility age (15-49), and men aged 15-54. The data include height measurements for more than 45,000 children, 120,000 women and 70,000 men. We show selected summary statistics in Panel (A) of Table 1. The low average growth performance of Indians is apparent in these figures: women were on average $152 \mathrm{~cm}$ tall, and average height was only $164 \mathrm{~cm}$ among men. Standardized measures of child growth performance (z-scores) were also very low, leading to the widely documented high rates of stunting (low height given age) and wasting (low weight given height) among Indian children.

To compare height performances and inter-generational gaps in height for ethnic Indians residing in England, we use the 1999 and 2004 rounds of the Health Survey for England (HSE). The survey was commissioned by the Department of Heath and conducted by the Joint Health Survey Units of the National Center for Social Research, and the Department of Epidemiology and Public Health of the University College, London. It is representative for the UK, and it provides a range of health indicators for the population living in private households. Both rounds include a specific focus on the health of minority ethnic groups living in England: in addition to the General Population sample, they include a minority ethnic "boost" sample generated by over-sampling areas with an important presence of ethnic minorities. The data also report if individuals belong to specific ethnic groups, including Indians, Pakistanis, and Bangladeshi.

The 1999 round randomly selected 6500 addresses (312 postal sectors) for the general population survey, and 26500 addresses (340 postal sectors) for the ethnic "boost", while HSE 2004 selected respectively 6,552 and 41,436 addresses. Within the general population sample, interviewers surveyed all adults (up to ten, in 2004), and up to two children per selected household. Within the ethnic boost sample, up to four adults per household were interviewed, and up to three children, randomly selected if necessary.

In addition to health indicators and anthropomorphic measurements (including height and weight), the survey provides information on ethnic origin, country of birth, age, and household socio-economic characteristics for all adults and children. For minority ethnic respondents, each interview was followed by the visit of a nurse, who also collected blood samples from individuals 
aged 11 and above. The survey reports weight for the entire sub-sample, and height starting from age 2 , in both rounds. In addition, birth weight was collected for children 2-15 in 1999 and 0-15 in 2004.

Pooling data from both HSE rounds is important to increase sample size and improve the precision of our estimates. In fact, while the data include height measurements for thousands of individuals, the number of ethnic Indian children below 5 is small (135 in total), also because children below 2 years of age were not measured. This limits the age range for which a comparison with NFHS data is possible (recall that in this latter data height, or better length, was instead measured for children below 2 years of age). An additional difficulty is that, for stated privacy reasons, month of birth is only available in HSE 1999, while it was concealed in HSE 2004. Therefore, and contrary to the previous analysis by Tarozzi (2008), we cannot construct precise standardized measures of height (the so-called 'z-scores'), and we will base all our results on raw height, in centimeters.

The key comparisons with HSE data will be between individuals identified as either "Indians" or "Whites". In both 1999 and 2004, a variable identified the ethnicity of each sampled individual as one among White, Black Caribbean, Black African, Indian, Pakistani, Bangladeshi, Chinese, or other. The 2004 survey also listed "Irish" separately but we re-code them as White for consistency. Someone identified as White may have been an immigrant, but this was rare: of a total of 18,665 individuals for whom the country of origin was reported in both surveys, 18,013 (96.5\%) were born in the United Kingdom or in the Republic of Ireland, 28 were born in India, 83 in Africa, and the rest in other countries (including other European countries). In our analysis we include all Whites regardless of the country of origin, but given that very few were born outside of the British Islands, the results would be almost identical if we excluded those who were not. ${ }^{3}$ Note also that almost all ethnic Indians in the HSE lived in households where every individual sampled shared the same ethnicity. Among children 2-17 year old, 24 of 812 (3\%) lived in mixed-ethnicity households, while 5 of $142(3.5 \%)$ did among children 2-4. The proportions were similar among adults with children. In our estimates we included all children identified as having Indian ethnicity regardless of whether they lived in mixed households, but there are so few of the latter that their exclusion would leave all results essentially unchanged. ${ }^{4}$

\footnotetext{
${ }^{3}$ Among men (women) age 18-50, average height was $176.7 \mathrm{cms}$. (163.1) regardless of whether we include Whites born outside of the British Islands. Among children 2-17, average differences between the two groups were less than $0.3 \mathrm{cms}$. for both genders.

${ }^{4}$ Note also that their small number means that the sample is too small to describe with reasonable precision how mixed-ethnicity parenthood is associated with height.
} 
We report selected summary statistics from HSE in panel (B) of Table 1. These figures already display the key empirical observations that form the core of this paper. First, ethnic Indians in England are much taller than their counterparts in India. Second, among adults living in England, Whites are much taller than Indians. Third, this latter gap disappears when we look at children, suggesting very fast catch up in height.

In order to expand the age range for which we can draw comparisons between residents of England and of India, we rely on an additional data set, the Indian Human Development Survey-II (IHDS-II). The IHDS-II, carried out in 2011-12, is the second round of a nationally representative survey that covers 42,152 households from 384 different districts of India, including all States and union territories except for Andaman/Nicobar and Lakshadweep (Desai and Vanneman 2015). This is a multi-topic survey covering health, education, employment, marriage status, fertility, gender relations, social capital, and socio-economic characteristics. The health section also includes anthropomorphic measurements for both children and adults. In an earlier round-IHDS-I, conducted in 2004-05-height measurements were available only for children up to 11 and for women 15 to 49. We thus choose to use data from IHDS-II because it allows us to expand the age range of observations, although a drawback is that this survey was conducted several years after NFHS-3, carried out in 2005-06. In Figures A.6 and Table A.12 in the Appendix we show that a comparison of child heights between IHDS-I and IHDS-II reveals improvements over time (especially among older children), so that using data from IHDS-I would have generated differences between children in India and ethnic Indians in England even larger that those we will document below. According to these data, in 2011-12 children under five were 0.5-2 centimeters taller than in 2005-06 (with the exception of newborn girls, who are estimated to be smaller), while among older children 8-11 the differences were in the range of $2-4$ centimeters. $^{5}$

As in HSE 2004, in IHDS-II the child's age in months was not recorded, so we cannot calculate z-scores and again we will only focus on raw height. We also set to missing a number of highly implausible measurements, identified - for each age and gender - as cases where height was more than five standard deviations from the median (513 cases, less than $0.5 \%$ of the total), or cases for children under 5 with height smaller than the minimum or larger than the maximum recorded in

\footnotetext{
${ }^{5}$ The analysis of the changes in average height between the two rounds of IHDS is beyond the scope of this paper, but it deserves to be scrutinized in future work, given that at the time of writing there is yet little information on the evolution of child anthropometric measurements in India after the completion of NFHS-3. Sinha (2015) discusses results from the Rapid Survey on Children, conducted in 2013-14, but at this time the micro data are yet to be released.
} 
NFHS-III (37 cases).

We report summary statistics from IHDS-II in panel (C) of Table 1. A comparison between average height in the 2-15 age group between IHDS-II and HSE again shows that children in India are remarkably less tall, while ethnic differences are not marked in HSE. However, there appear to be puzzling differences in the average height of children under 5 between IHDS-II and NFHS-3, with the means higher by about 3 centimeters in the latter data set, despite the fact that the data were collected about five years earlier. In Figure A.7 we show that the differences are present for both boys and girls, and at all ages. As we have mentioned earlier, average heights were even smaller in IHDS-I, which would have further exacerbated the gap between the two data sets. We cannot determine the specific reasons for these differences, which may be due to differences in sampling or in measurements, but there is strong evidence that anthropometric measurements in IHDS were taken rather coarsely, an observation that perhaps also explains the larger standard deviations of height in IHDS relative to NFHS, and that needs to be kept in mind when interpreting results from IHDS-II data. ${ }^{6}$ In fact, a histogram of measured height for children (0-18) shows very evident spikes at multiples of 10 centimeters, not what should be observed if appropriate measurements had been recorded, see Figure A.8 in the Appendix. ${ }^{7}$ It is not clear why this kind of measurement error should have generated systematically lower estimates of height, but these patterns raise concerns about the quality of the height data from IHDS.

\section{Adult Height and Selection into Migration}

In this section, we analyze data on adults from HSE and NFHS with two main objectives. First, we look at differences in height between adults in India and ethnic Indians in England, with the purpose of studying height selection into migration. Second, we compare adult ethnic Indians and Whites in England to document the existence of large average differences between these two ethnic groups.

One important although somewhat obvious consideration in interpreting our findings is that

\footnotetext{
${ }^{6}$ Differences in the distribution of anthropometric outcomes have also been observed between data from NFHS and from the National Nutrition Monitoring Bureau (NNMB): Deaton and Drèze (2009) estimated the prevalence of stunting for all children - regardless of gender - at 45\% in NFHS-3 (2005-06) and 52\% in NNMB data (2004-05), a gap that was not simply explained by differences in the sampling frame adopted in the two surveys.

${ }^{7}$ Measurements of weight suffer from a similar problem. Spikes are also evident in IHDS-I data, while they are not in NFHS data.
} 
migration is by no means a random event. In particular, consistent with the hypothesis that economic migrants from distant and poorer countries have better human capital that the average in their country of origin (Chiswick 1999, Chiquiar and Hanson 2005), we expected South Asian immigrants in England to be on average positively selected on height. It is less clear that we should expect migrants to differ systematically from the overall population in terms of height genetic potential, where we use this terminology to indicate the height that an individual would achieve under ideal conditions in terms of both nutrition and infection experiences throughout his/her life. ${ }^{8}$ Still, it is hard to rule out completely the possibility of positive selection in terms of potential. For instance, although achieved height depends on many factors, we still expect individuals with a higher genetic potential to be on average taller. And given the often documented positive return to height for labor market outcomes, which in turn are likely correlated with migration, a correlation between migration and genetic potential in terms of height may emerge.

In Figure 1 we show estimates of average height of adult women and men, by cohorts, together with $95 \%$ confidence bands. For each gender, we show separate estimates for adults measured in NFHS-3, ethnic Indians in England and Whites in England. Here as well as in the sequel we always pool together all observations from HSE 1999 and 2004 to improve the precision of the estimates, given that sample sizes are relatively small. We show results for different cohorts, defined by 5-year groups of year of birth, both to improve precision and to limit measurement error given that adult age in NFHS data show a distribution with clear peaks at multiples of five, surely the result of reporting errors that are disproportionately more common among individuals with low literacy (see Figures A.9 and A.10 in the Appendix). ${ }^{9}$

Several patterns emerge from the pictures. First, among adults living in England, Whites are substantially taller than ethnic Indians, with large and similar differences in average height for all age groups: pooling all cohorts together we estimate that White men and women were on average respectively 176.9 and $163.2 \mathrm{~cm}$ tall, while among ethnic Indians the corresponding averages were 171.8 and 157.2. Second, even larger differences are observed between adult Indians in NFHS-3

\footnotetext{
${ }^{8}$ Given current knowledge, this concept is still fundamentally unobservable, both because few individuals live in such ideal world, and because the association between height and genes is complex and is not yet completely understood, despite progress in the analysis of the human genome (see Wood et al. 2014).

${ }^{9}$ Note that all Indians in NFHS-3 used to construct the estimates likely already achieved their adult height, given that the youngest (born in 1982) were already 23 or older at the time of being measured in 2005-06. In contrast, it is likely that some individuals living in England had not yet achieved their adult height, but only in the $1978-82$ cohort: some of these individuals were measured in 1999 and were therefore 17 at the time of the survey.
} 
and ethnic Indians in England: in NFHS data, the average man was only $164.6 \mathrm{~cm}$ tall, while among women average height was $151.9 \mathrm{~cm}$. Large differences remain, albeit reduced, if we use NFHS-3 data to estimate average heights in selected states where adults tend to be taller: for instance in Punjab men were $168.6 \mathrm{~cm}$ tall while women were $154.7 \mathrm{~cm}$ on average. ${ }^{10}$ A third interesting observation is that the difference in height between Indian adults measured in NFHS-3 and ethnic Indians in England has not visibly narrowed among individuals born in the 20-year period 1960-1980.

The estimates in Figure 1 for ethnic Indians in England remain almost identical if we only include individuals who migrated into Britain when they were older than 20, that is, after they likely achieved their adult height, see Figure A.11 in the Appendix. This result is overall consistent with findings from the well-studied Mexican immigration into the United States. Both Crimmins et al. (2005) and Riosmena et al. (2013) find that Mexicans with a migration history in the United States are taller than others without, although Rubalcava et al. (2008) documents positive selection into migration only among women migrating from urban Mexico between 2002 and 2005.

Data on schooling levels of ethnic Indians in England are again consistent with positive selection. When we look at the 1,296 ethnic Indians 25 or older in our sample who migrated to Britain when they were at least 20 years old, we find that almost half of them were 19 or older when they finished full time education. This is also consistent with research that shows that ethnic Indians in the United Kingdom outperform most other ethnic minorities (and in some dimensions even natives) in terms of both labor market outcomes and schooling achievements, see for instance Dustmann et al. (2011). Schooling achievement was recorded in very different ways in HSE and NFHS, so a straightforward comparison is not possible, but despite this the positive selection on education is apparent. Among the 145,280 adults older than 25 in our NFHS-3 sample, 38\% had no education and only $10 \%$ achieved more than a secondary school degree.

The HSE also includes information of numerous health indicators besides height, but unlike height such outcomes are not time-invariant and thus cannot be used to study health selection into migration. Despite this limitation, we think it is interesting to look at hemoglobin levels (Hb), given that anemia is a widespread health condition in India, is often caused or worsened by inadequate nutrition, and can lead to poor birth outcomes when present during pregnancy. ${ }^{11}$ Recent research

\footnotetext{
${ }^{10}$ The HSE does not indicate the state of origin of ethnic Indian immigrants. Limited information is available about language spoken but this does not allow to identify with confidence the state of origin and so we do not use these records.

${ }^{11}$ Anemia is characterized by a reduced number of red blood cells or by a low concentration of hemoglobin, leading
} 
has suggested that the poor nutritional status of mothers may be a key contributing factor for the high rates of undernutrition in India, see Coffey (2015b).

In Figure 2 we show estimates of mean Hb by age group and gender, separately for NFHS-3 and for Whites and ethnic Indians living in England. In this case, however, the estimates for Whites need to be considered with caution, because blood samples for measuring $\mathrm{Hb}$ were collected only for a fraction of individuals who may thus not have been representative of the underlying population. ${ }^{12}$ In addition, the HSE only measured Hb for persons older than 10, while NFHS-3 only tested children up to 5 and adults (women 15-49 and a random subset of men 15-54). There is thus only partial overlap in the age distribution of tested individuals between surveys, although for completeness we estimate results also for age groups that were only present in either India or England.

Hemoglobin levels are on average remarkably low (and similar between genders) among Indian children tested in NFHS-3, a phenomenon already widely known that translates into very high prevalence of anemia, see for instance Tarozzi (2012). Hemoglobin levels are significantly higher on average among older individuals in India, but they are enormously lower for women relative to men. This kind of gender gap typically appears once girls reach puberty, and is often observed both in poor and rich countries, although it is usually significantly more marked in developing countries, where nutrition and/or micro-nutrient supplementation do not adequately compensate for the increased requirements caused by menstruation and childbirth.

When we look at data from England, a first observation is that there are large differences between Ethnic Indian women in this country and women in India (the average difference is 0.88 $\mathrm{g} / \mathrm{dl}$ ). The gap is higher at younger ages, peaking to $1.07 \mathrm{~g} / \mathrm{dl}$ blood at age 25 , and then decreases. The difference in Hb levels is slightly smaller for men, in the order of $0.72 \mathrm{~g} / \mathrm{dl}$ blood on average

to reduced capacity to transport oxygen to body cells. Its adverse effects include chronic fatigue, impaired learning and cognitive development among children and even increased mortality in severe cases (especially during childbirth). It is one of the most common forms of malnutrition, affecting about one third of the world population (McLean et al. 2009). Iron deficiency is the main cause of anemia worldwide, but anemia can also be caused by an insufficient intake of other micro-nutrients such as Vitamin A and B12, or by infections such as malaria or intestinal worms. There is no universally accepted definition of anemia, but often 'moderate' anemia is identified by Hb levels below a threshold that can depend on gender, age, and altitude, but is usually around 11-12 grams per deciliter of blood.

${ }^{12}$ In 1999, a nurse was scheduled to re-visit all households from ethnic minorities and also entrusted with collecting the blood samples. Only a subset of non-minorities where instead re-visited, with blood samples taken only for individuals 35 and older. In practice, Hb was also measured for 262 individuals age 11-34 from 'White' households. In 2004, Whites were only tested if the household was categorized as 'Irish'. 
across ages. There is overall a moderate difference between Indians and White males, with both groups doing better than males in India, with the difference being a bit below $1 \mathrm{~g} / \mathrm{dl}$ blood. The higher $\mathrm{Hb}$ levels in England relative to India are also present among women, but while ethnic Indians do significantly better than their counterparts living in India, they also do significantly worse than White women in England. For several age groups, the difference by ethnicity is as large or larger than $1 \mathrm{~g} / \mathrm{dl}$. That such differences within England are only observed among women raises interesting questions on the persistence of gender roles and preferences imported from the country or origin, although we will not pursue this in any detail in this article. Earlier research has found evidence consistent with the persistence of son-biased sex ratios among Indians at high parity, both in England and Wales (Dubuc and Coleman 2007), the United States (Almond and Edlund 2008) and Spain (González 2016).

\section{Child Height and Ethnicity}

In the previous section we have shown that ethnic Indian adults of both genders living in England are significantly less tall than Whites. If those differences were largely due to genetic factors, we would expect them to persist among their sons and daughters. In addition, even in the absence of ethnic differences in genetic potential for height, and even if England provided on average a socio-economic and epidemiological environment more conducive to child physical growth than India, catch up growth may be slowed down if mother's low achieved height is transmitted to her children. This is the basis of the "gradual catch-up hypothesis," as described by Deaton and Drèze (2009). Slow catch up may emerge because child height is influenced by birthweight and this, in turn, is highly correlated with mother's weight and height.

In this section we thus extend our comparisons to children. In Section 4.1 we use data from NFHS-3 and HSE to look at children under five, a critical age group that has been at the center of much of the debate on the small average stature of Indians. As for adults, we analyze differences between ethnic Indian children in England on the one hand, and both India and Whites in England on the other hand. Next, in Section 4.2 we use data from IHDS-II in order to extend the comparisons to a broader age range (0-18).

Before proceeding, note that here we look at the height of children in our data regardless of whether they were sons and daughters of the adults included in the analysis of the previous section. If there were height selection into parenthood, differences in the relative height performance of 
adults vs. children could be caused by parents of different height having different probability of having children. However, we find little evidence of such form of selection, as shown in Appendix Table A.10. In Section 5 we will also build an explicit link between the height of children and that of their parents.

\subsection{Comparisons using NFHS-3 Data}

We first draw comparisons between the height of children in ethnic Indian families in England and Indian children from NFHS-3. This latter survey includes only height measures for children younger than 5. This implies that there is limited age overlap with HSE, where instead height was recorded only from age 2 onwards. An additional limitation is that HSE 2004 did not record the age of children in months, making it impossible to calculate precise standardized anthropometric indicators comparable across age and gender groups. We thus base our comparisons on age in years. The comparison between the two different data sources will remain meaningful under the plausible assumption that the distribution of age in months conditional on age in years is not systematically different in HSE and NFHS-3.

We show graphically average height by age and gender in Figure 3, while Table 2 includes the full results. The first apparent pattern is that children of English ethnicity are significantly taller than their counterpart in India. For instance, the average 4-year old White boy in England was $105.2 \mathrm{~cm}$. tall, while the average Indian boy in NFHS-3 was only $97.9 \mathrm{~cm}$. tall (that is, $7 \%$ less). Among girls, average height at the same age was 104.9 centimeters for Whites in England, and only 96.4 (about 8\% less) in India. Given the well documented gap between child height in India and international standards, these results are not surprising.

Less expected is the observation that height is remarkably similar between ethnic groups when we compare the height of White and ethnic Indian children in England, so that the null of equality is never rejected, see column 6 of Table 2. In contrast, the null of equality is always rejected at all standard significance levels when we compare ethnic Indian children in England with Indian children measured in NFHS-3, see column 8. These findings are consistent with the results in Tarozzi (2008), who showed that the prevalence of stunting and wasting in HSE 1999 were very similar between White and ethnic Indian children born and raised in England.

That the null of equality (in column 6) is never rejected is surely also a consequence of the small number of 2 to 4 year-old children of Indian ethnicity in the sample, but the differences are truly small in magnitude, and in a number of cases children of Indian ethnicity are actually 
on average slightly taller than Whites. The results are also very similar when we pool together ethnic Indians with children from immigrant families from Pakistan and Bangladesh, the other two countries responsible for the so-called 'South Asian Enigma'. Indeed, when we use this larger sample, estimates are sufficiently precise that the null of equality between Whites and South Asians is rejected for 4-year old boys, but for this demographic group it is the South Asian who have a (small) advantage.

We thus find that one generation was all it took to erase the substantial differences in height observed among adults between ethnic Indians and Whites in England. This finding provides evidence against the hypothesis that the South Asian Enigma has genetic origins, although they do not conclusively rule it out. In fact, although Indian adult immigrants in England tend to be smaller than Whites, we cannot exclude that they were positively selected not only on height (a fact strongly supported by the data) but also on genetic potential for height (which we cannot observe). In other words, we cannot infer from our results that the gap with Whites in England would on average disappear if (rather implausibly) the average conditions in England could be replicated across India.

These results are also consistent with remarkably rapid catch up of growth performances among ethnic Indians with those observed in a rich geographical area such as England. Once again, however, one cannot extrapolate too much from these results. First, as immigrants may be positively selected on genetic potential for height they may also be positively selected on their potential for generating children that, under suitable conditions, can achieve such genetic potential. In other words, they may be selected on their ability to produce rapid, rather than gradual, catch up. Second, our data so far allow us to compare the height gap between ethnic groups among adults and among their children, but the fact that the gap has disappeared among the latter does not imply that the gap will not exist when these children grow up to be adults. The association between height in early childhood and in adulthood is not perfect, although a number of studies show that interventions to address stunting tend to have limited efficacy after age 2-4, see for instance Martorell and Habicht (1986), Martorell et al. (1994), Schroeder et al. (1995). Finally, even if the catch up growth among children were reflected in equally complete catch up in adulthood, it remains true that their parents were substantially taller than adults in NFHS-3. Hence, even if we were sure that there is no positive selection on height genetic potential among ethnic Indians in England, and if (again, rather implausibly) the average conditions in England could be replicated across India, it may take more than one generation to erase the growth gap. 
A related point is that, in our data, we cannot label all ethnic Indian children as 'second generation' immigrants, given that many of their parents where themselves not born in India. When we look at children 2 to 4 of Indian ethnicity for whom information on their parents' place of birth is available, we find that only about 40 percent of them had parents born in India. The proportion is about 10 percentage points higher when we look at children 2-18.

\subsection{Comparisons using IHDS Data}

One drawback of comparing data from HSE and NHFS is the limited overlap in the age range for children in the two data sets. To address this shortcoming, we make use of data from the 2011-12 Indian Human Development Survey (IHDS), although we have noted earlier that there are concerns with the reliability of height in this data set. Figure 4 shows the graphical comparisons of statures using the usual format, with $95 \%$ confidence bands around each age-specific estimate. The point estimates, standard errors and sample size for each group are displayed in Table 3. Up to age 4, the estimates from HSE are the same as in Figure 3, but here we also look at older children, up to age 18. For most ages we only have 15-30 observations of a given gender for ethnic Indians in England, resulting in imprecise estimates, but despite this the comparisons are informative.

Once again we see a very large height gap when we compare data from India with those from England. At most ages, ethnic Indians in England are more that 10 centimeters taller than their counterparts in IHDS. For instance, 10-year old boys are on average $129.1 \mathrm{~cm}$ tall in IHDS, and $141.5 \mathrm{~cm}$ in HSE, while among 15-year old the mean heights are 156.8 and 170.4 in the groups respectively. Looking across age groups, ethnic Indian boys are 5 to $16 \%$ taller in England than in India (9.4\% taller on average), while among girls the gap ranges between 5 and $14 \%$ (8.7\% on average). For both genders, the largest relative differences are found for very young children of age 2 and 3 .

Moving next to the comparison of height between ethnic Indians and Whites in England, we find that differences are negligible among younger children, although ethnic Indians start to be systematically smaller when they approach the 'teen' years. Among boys, ethnic Indians are on average smaller than Whites at ages 12 and above, although the differences are imprecisely estimated and do not increase monotonically with age. Also among girls, Whites have a systematic advantage starting age 12, and also in this case the gap does not charge uniformly with age.

Note that the appearance of height gaps among older children cannot be explained by them being more likely to have migrated to England later on in life, because in our estimates we have 
only included children born in England. However, these simple comparisons do not control for any parental characteristics such as education or income or, perhaps more importantly, height. In the next section we thus turn to studying more explicitly the association between parental and child height in England versus in India.

\section{Inter-generational Transmission of Body Size in Indian Families}

The previous sections have shown that the comparable height performance between very young children of White and of Indian ethnicity in England can only be partly attributed to selective migration of taller parents. In this section we look more explicitly at the intergenerational association of parental and child height. We do so by pooling data on Indians from the HSE 1999 and 2004 and, respectively, the NFHS-3 or the IHDS-II, and we estimate variations of the following model:

$$
\ln H_{a, i}^{C}=\theta_{0}+\theta_{1} \ln H_{i}^{M}+\theta_{2} \ln H_{i}^{F}+\theta_{3} E n g_{i}+\theta_{a}+\varepsilon_{i}
$$

where $H_{a, i}^{C}$ is the height of child $i$ of age (in years) $a, H_{i}^{M}$ and $H_{i}^{F}$ are the heights of the mother and father respectively, $\theta_{a}$ is an age dummy, and Eng is a dummy variable that takes value 1 if the child belongs to the sample of Indian migrants in England and 0 if s/he belongs to the general population in India. The key coefficient of interest is $\theta_{3}$, which can be interpreted as the predicted (percentage) difference in child height between children in India and ethnic Indians in England, conditional on age and parental height. It would be tempting to interpret this coefficient as the 'height return to England', but as we have stressed earlier, this simple regression does not control for a number of confounders, such as the height genetic potential, or even possible heterogeneity in the ability to catch up speedily to such genetic potential.

As a reminder, the HSE data report height measures starting from children of age 2, while NFHS-3 reports height only for children below 5. Hence, when we base the analysis on NFHS-3 and HSE, we only use information from children age 2 to 4 . In contrast, IHDS-II reports height measures at all ages, allowing us to expand the sample to children aged 2-18. We estimate equation (1) with OLS, separately for boys and girls.

While maternal height was usually recorded, that of the father is often missing. We thus estimate the regressions above both controlling only for maternal height, which allows us to use a larger sample, and controlling for the height of both parents. To enhance comparability across specifications we also show results where we use the smaller sample for which the height of both parents is available, but where we include only mother's height as control. We do not include 
controls for parental education and socio-economic status because the Indian and England surveys are not easily comparable in these respects. We cluster standard errors at the primary sampling unit, consistently with the survey design. All regressions include survey weights to account for the relative probability of minorities in the England sample, and to have nationally representative samples for both surveys. In each regression, the sampling weights for observations from each data set are re-scaled, in a way to make their sum equal to the number of observations from that data set that are included in the regression. Table 4 reports the regression results obtained from estimating equation (1) on the sub-samples of girls and boys from NFHS-3 and HSE 1999 and 2004 for which the height of the mother (columns 1 and 4) or that of both parents (in the other columns) is not missing.

Our first result is that children with Indian origins born in England are 7-8\% taller than their counterparts from the general population in India, conditional on age and mother's height (columns 1 and 4). This holds both for boys and for girls, and is consistent with what we were observing by simply comparing average height-by-age in section 4 . Despite the relatively small number of observations from HSE (see Table 1), the estimates are very precise, with standard errors of less than 1 percentage point, so the coefficient is significant at any standard level. As expected, maternal height is a powerful predictor of child height, with an elasticity of about 0.4 for both genders. The results are very similar when we use only observations for which the height of both parents is available (columns 2 and 5$).{ }^{13}$

The estimates of $\hat{\theta}_{3}$ decrease slightly when we control for the height of both parents (columns 3 and 6 ), but the coefficients remain large, above $6 \%$ for both boys and girls, and significant at any standard level. If we estimate separate regressions by age, the estimates remain similarly large and significant at each age and for both genders, with the smallest coefficient being $\hat{\theta}_{3}=0.044$ for 4-year old boys, see Appendix Table A.11. Note also that, consistent with the large literature that documents the central role played by mother's body size for child physical growth, we find that the elasticity of child height with respect to maternal height $(0.35-0.39)$ is much larger than the elasticity with respect to paternal height (about $0.26-0.27) .{ }^{14}$

\footnotetext{
${ }^{13}$ The results are also very similar if we control for the age of the mother at birth or the age of both parents at birth. In particular the young age of the mother at birth is often an indicator of low socio-economic status and education. These results are available upon request from the authors.

${ }^{14}$ Note also that the inclusion of father's height reduces the coefficient related to mother's height (compare columns 2 and 3 , or 5 and 6 ). This is not surprising given the likely presence of assortative mating in the marriage market. In fact, this is confirmed when we look directly at the correlation between (log) parents' heights. In HSE data,
} 
In order to look at the intergenerational association of height over a broader age spectrum, we move next to analyzing the IHDS-II and HSE samples including children aged 2 to 18 . Table 5 reports OLS estimation results. Despite the concerns on the quality of the height data in IHDS that we have highlighted earlier, these results are overall similar to those we obtained using NFHS-3 data. Indian children in England are 7-9\% taller than those in India (with standard errors of 0.5\% or below), conditional on age and parental height. Note that these regressions also show that the elasticity of child height with respect to paternal height is about $50 \%$ larger than with respect to maternal height, a result that is somewhat unexpected.

Table 6 reports the results estimated on a smaller sample that includes only children aged 2-4, for symmetry with the NFHS vs HSE case (see table 4 for comparison). In this case, the estimated coefficients $\hat{\theta_{3}}$ become much larger then when we also include older children. When we control for the height of both parents, the magnitude become 0.13 for girls (s.e. 1.4\%) and 0.12 for boys (s.e. 1.3\%). These estimates are about twice as large as those obtained using NFHS data, surely a consequence of the substantially smaller heights recorded in IHDS for children in this age range relative to NFHS-3, see Figure A.7. Note also the surprising results that the elasticity of child height on maternal height is small and even not significant in some of the regressions, with even a negative sign in the model for girls when we include both parents' height. In contrast, the elasticity of child height with respect to paternal height is statistically significant at the $1 \%$ level in all cases, and larger in magnitude than for maternal height. Overall, these results cast further doubts on the reliability of the height measurements in IHDS.

\subsection{Robustness Checks with Matching}

Going back to the comparisons between NFHS-3 and HSE data, we also explore differences in height between ethnic Indian children in England and their counterparts in India, but using a more explicit matching procedure. ${ }^{15}$ We focus here on the younger children at least 2 but less than 5 years old.

We proceed by comparing first ethnic Indian children from HSE with children from NFHS-3 who have the same age (in years) and gender, and whose mother was at least as tall as the mother of the child in HSE. This is an ad-hoc procedure, but we prefer it to a more standard matching the correlation for ethnic Indian parents is 0.37 (significant at the $1 \%$ level). Interestingly, it is only 0.25 among Whites. The same correlation estimated using NFHS-3 data is about 0.20 , again significant at the $1 \%$ level, and similar between rural and urban sectors.

${ }^{15}$ We thank Zahra Siddique for suggesting this strategy to us. 
algorithm because it likely biases the results against the key finding in our analysis that children of Indian ethnicity are substantially taller in England. We then conduct a similar matching but using, as a comparison group, children in NFHS-3 whose mother and father were at least as tall as the parents of the child in England. We show the results in Table 7, where we do not report standard errors given that the ad-hoc matching procedure generates sampling variability that is difficult to evaluate.

For both boys and girls, and at all ages, the height gaps between ethnic Indians in England and Indian children in NFHS-3 are very large, although as usual we have to contend with the very small sample sizes. When we match only based on mother's height (panel A), the average differences range from a minimum of 3 centimeters for 4 -year old boys (which amounts to $3 \%$ of the average height of children in this age category in NFHS-3, see Table 2), to a maximum of 6.7 centimeters among 2-year old girls (or $8 \%$ of the similarly defined reference group). The differences become smaller but remain substantively large (with the exception of 4-year old boys) when we also match on paternal height (panel B). In sum, even with this kind of child-by-child matching, we thus find confirmed a substantial relative height advantage of ethnic Indian children in England conditional on the height of their parents.

\subsection{Birth Weight}

In Figure 3 we have shown that among 2 to 4 -year old children in England there is very little difference in height between ethnic Indians and Whites. This is remarkable, given that we have also shown that, in contrast, adult Whites are significantly taller than ethnic Indians. Because small mothers are less likely to give birth to 'large' healthy babies, a higher degree of persistence may have been expected.

Both HSE surveys recorded the birth weight of children below age 15 (and only for children older than 2 in 1999). In this age group, there are a total of 4,606 individuals, of which 856 are ethnic Indians. Birth weight was recorded for $88 \%$ of this sample, and neither gender nor ethnicity predict missing values for this variable, see column 1 of Table 8 . In contrast, in column 2 we show that birth weight is very different between ethnicities. Average weight for White boys at birth was 3.45 kilograms, while among ethnic Indians it was about 400 grams (or 12\%) smaller. Similarly, the average birthweight of girls was 3.31 kilograms among Whites and only 2.9 (14\% less) among ethnic Indians. The differences are substantively large and significant at any standard level. Note also that the results are not driven by ethnic Indians born abroad, given that the estimates are 
almost identical if we only include information from children born in UK or Ireland, see column 3. In addition, although birth weight was reported by the respondent and not derived from official records, there is little evidence of systematic reporting error as would be suggested, for instance, by peaking at focal figures, see Figure 5 . These histograms also show that the average differences are not the result of outliers with very low birth weight. In fact, for both genders, the whole distributions among ethnic Indians appear shifted to the left relative to those for Whites.

When we look at the association between birth weight and parental body size, we find that the low birth weight of ethnic Indian babies is strongly correlated with the small body size of their mothers. If we pool together all children, we find that the elasticity of birth weight with respect to mother's height is 1.2 , with a standard error of 0.1 , see column 1 of Table 9 . The estimate remains slightly above 1 even when we control for mother's weight, both the height and the weight of the father, and a full set of primary sampling unit fixed effects (column 5). Strikingly, father's height is not significant at standard levels when parents' weight is included in the regressions. Given that ethnic Indian mothers are about $4 \%$ less tall than White mothers (see Section 3), about one third of the ethnic gap in birth weight is thus explained by mother's height. ${ }^{16}$

Overall, these results thus show that children of ethnic Indians are significantly smaller than Whites if one looks at birth weight, although our analysis suggests that such differences do not translate into height gaps, at least until adolescence.

\section{Concluding Remarks}

This paper presents empirical evidence on the comparative height performances of adults and children of Indian ethnicity in England, relative to adults and children in India, and relative to the native population of Whites in the destination country. First, we show that adult migrants in England are positively self-selected in terms of height with respect to the population of origin, with an average advantage of 6 to $7 \mathrm{~cm}$. In contrast, relative to natives at destination, adult migrants in England are substantially smaller. If those differences were mainly caused by genetic factors, we would expect them to persist among their children. However, this is not what we find: the difference between natives and ethnic Indians in England disappears among younger children, although it re-appears among older children. When we look at birth weight, we find that children

\footnotetext{
${ }^{16}$ In principle, different rates of premature births could also explain part of the gap. Unfortunately, information on gestation duration is missing for more than 90 percent of observations. Still, in the limited information available there is no evidence that ethnic Indian children were disproportionately likely to be born prematurely.
} 
of ethnic Indians have much smaller birthweight than Whites, by about 0.4 kilograms on average. As next step, we show that Indian children in England are 6 to $8 \%$ taller relative to the population of origin, conditional on age, gender and parental height.

Our results are consistent with earlier work that has found that the intergenerational transmission of poor health can be mitigated by favorable conditions during growth, suggesting that growing up in more developed areas can be a substitute for factors inherited from parents. Bhalotra and Rawlings (2013) use data from a large number of developing countries to show that children are more likely to be negatively affected by poor maternal health when they are born in adverse socioeconomic conditions. Similarly, Currie and Moretti (2007) find that the correlation between mother and children's birthweight is stronger among poorer relative to better off mothers. Kim et al. (2015) find that the correlation of adult health measures with their parents' health status and mortality are weakened in richer areas. In contrast, Dolton and Xiao (2015) show that the intergenerational correlation of obesity in China is similar across families of different socio-economic status, while being higher among children with high body mass index (BMI).

We conclude by highlighting a number of limitations in our findings. First, although our results provide evidence against the importance of genetic factors in explaining the South Asia puzzle, they do not completely rule out that such factors could play a role. We have seen that there is very strong positive selection in height of ethnic Indian immigrants, and we cannot exclude that there may also be selection in genetic potential, and/or in the ability to reach such potential in the presence of favorable socio-economic and epidemiological conditions.

Second, and related, children under 5 have been the focus of much of the debate on the poor health status of Indian children, and in this age group we find no systematic disadvantage between ethnic Indians and Whites in England. However, even among ethnic Indians born in England, we do find a gap at older ages, approximately after puberty. Explaining these patterns goes beyond the scope of this paper but it raises interesting questions. For instance, this could be related to the large disadvantage in birth weight that does exist between children born from ethnic Indian versus White mothers. However, it is also impossible to exclude that genetic factors play a role. Evidence from several studies of monozygotic and dizygotic twins show that a large fraction of the variation in height is explained by genetic factors, with the fraction increasing from $20-50 \%$ in infancy to 70-90\% among adolescents and adults (Dubois et al. 2012), and with similar heritability among individuals with different ethnic background from North-America, Australia, and East-Asia (Jelenkovic et al. 2016). The similarity between Whites and ethnic Indians in England among 
younger children could thus be driven by the relatively large role of environmental factors in this age group relative to older children. However, we never observe the adolescent or adult height of the young children in our sample, so we cannot determine if their height will be comparable to that of the native White population when they reach older ages.

Third, we do not speak to why we observe such rapid catch up, whether it is better nutrition, better pre or post-natal care, breastfeeding practices, epidemiological environment for the mother and the child, or whether Indian migrants also positively select on the epigenetic reaction to the environment. Plausibly, the effect encompasses to some extent all of the above explanations.

Fourth, the key comparisons in our analysis are between Indians, or ethnic Indians, and 'Whites' in England. This is strictly related to, but not the same thing as, comparing the former groups to the international standards that are widely utilized to gauge the overall growth performance across populations. In particular, when we look at children, we do not base our comparisons on z-scores, because these cannot be calculated for HSE 2004 .

Last but not least, despite the over-sampling of ethnic minorities in the two HSE we use in the paper, the number of children of Indian ethnicity remains very small. This leads to imprecise estimates, although in most cases the gaps between populations are so large that the null of equality between mean heights can be rejected at standard levels. 


\section{References}

Agarwal, K., D. Agarwal, D. Benakappa, S. M. Gupta, P. C. Khanduja, S. P. Khatua, K. Ramachandran, P. M. Udani, and C. Gopalan (1991). Growth Performance of Affluent Indian Children (Under-Fives): Growth Standards for Indian Children. Nutrition Foundation of India, New Delhi.

Almond, D. and L. Edlund (2008). Son-biased sex ratios in the 2000 United States Census. Proceedings of the National Academy of Sciences 105(15), 5681-5682.

Atkin, D. (2013). Trade, tastes and nutrition in India. American Economic Review 103(5), 1629-1663.

Atkin, D. (2016). The caloric costs of culture: Evidence from Indian migrants. American Economic Review $106(4), 1144-81$.

Bhalotra, S. and S. Rawlings (2011). Intergenerational persistence in health in developing countries: The penalty of gender inequality? Journal of Public Economics 95(3-4), 286-299.

Bhalotra, S. and S. Rawlings (2013). Gradients of intergenerational transmission of health in developing countries. Review of Economics and Statistics 95(2), 660-672.

Bhalotra, S., C. Valente, and A. van Soest (2010). The puzzle of Muslim advantage in child survival in India. Journal of Health Economics 29(2), 191-204.

Bhandari, N., R. Bahl, S. Taneja, M. de Onis, and M. K. Bhan (2002). Growth performance of affluent Indian children is similar to that in developed countries. Bulletin of the World Health Organization 80(3), $189-195$.

Boas, F. (1912). Changes in the bodily form of descendants of immigrants. American Anthropologist 14, $530-562$.

Chiquiar, D. and G. H. Hanson (2005). International migration, self-selection, and the distribution of wages: Evidence from Mexico and the United States. Journal of Political Economy 113(2).

Chiswick, B. R. (1978). The effect of americanization on the earnings of foreign-born men. Journal of Political Economy 86(5), 897-921.

Chiswick, B. R. (1999). Are immigrants favorably self-selected? American Economic Review 89, 181-185.

Coffey, D. (2015a). Early life mortality and height in Indian states. Economics and Human Biology 17, $177-189$.

Coffey, D. (2015b). Prepregnancy body mass and weight gain during pregnancy in India and sub-Saharan Africa. Proceedings of the National Academy of Sciences 112(11), 3302-3307.

Coffey, D., A. Deaton, J. Drèze, D. Spears, and A. Tarozzi (2013). Stunting among children: Facts and implications. Economic and Political Weekly XLVIII(34), 68-70.

Coffey, D., R. Khera, and D. Spears (2015). Intergenerational effects of women's status: Evidence from joint Indian households. Working Paper.

Crimmins, E., B. Soldo, J. K. Kim, and D. Alley (2005). Using anthropometric indicators for Mexicans in the United States and Mexico to understand the selection of migrants and the "Hispanic Paradox". Social Biology 52(3/4), 164-177.

Currie, J. and E. Moretti (2007). Biology as destiny? short-and long-run determinants of intergenerational transmission of birth weight. Journal of Labor Economics 25(2), 231-264.

Deaton, A. (2007). Height, health, and development. Proceedings of the National Academy of Sciences $104(33), 13232-13237$. 
Deaton, A. and J. Drèze (2009). Nutrition in India: Facts and interpretations. Economic and Political Weekly $X \operatorname{LIV}(7), 42-65$.

Desai, S. and R. Vanneman (2015). India Human Development Survey - II, 2011-12. ICPSR36151-v1. Ann Arbor, MI: Inter-university Consortium for Political and Social Research.

Dolton, P. and M. Xiao (2015). The intergenerational transmission of BMI in China. Economics and Human Biology 19, 90-113.

Dubois, L., K. Ohm Kyvik, M. Girard, F. Tatone-Tokuda, D. Pérusse, J. Hjelmborg, A. Skytthe, F. Rasmussen, M. J. Wright, P. Lichtenstein, and N. G. Martin (2012). Genetic and environmental contributions to weight, height, and BMI from birth to 19 years of age: An international study of over 12,000 twin pairs. PLoS ONE 7(2), 1-12.

Dubuc, S. and D. Coleman (2007). An increase in the sex ratio of births to India-born mothers in England and Wales: Evidence for sex-selective abortion. Population and Development Review 33(2), 383-400.

Dustmann, C., T. Frattini, and N. Theodoropoulos (2011). Ethnicity and second generation immigrants. In P. Gregg and J. Wadsworth (Eds.), The Labour Market in Winter: the state of working Britain, Chapter 15. Oxford University Press.

Farré, L. (2016). The healthy immigrant effect: Evidence from the Ecuadorian exodus. Journal of Population Economics 29(2), 365-394.

Feliciano, C. (2005). Educational selectivity in U.S. immigration: How do immigrants compare to those left behind? Demography 42(1), 131-152.

Fogel, R. W. (1994). Economic growth, population theory, and physiology: The bearing of long-term processes on the making of economic policy. American Economic Review 84(3), 369-395.

González, L. (2016). Sex selection and health at birth among Indian immigrant. Working Paper. Universitat Pompeu Fabra and Barcelona GSE.

Gravlee, C., R. Bernard, and W. Leonard (2003). New answers to old questions: Did Boas get it right? Heredity, environment, and cranial form: A reanalysis of Boas's immigrant data. American Anthropologist 105(1), 125-138.

Habicht, J.-P., C. Yarbrough, R. Martorell, R. M. Malina, and R. E. Klein (1974). Height and weight standards for preschool children: how relevant are ethnic differences in growth potential? The Lancet 303(7858), 611-615.

Hatton, T. and B. Bray (2010). Long-run trends in the heights of European men, 19th-20th centuries. Economics and Human Biology 8, 405-13.

IIPS (2007). National Family Health Survey (NFHS-3), 2005-06: India: Volume I. Mumbai: International Institute for Population Sciences and Macro International.

Jayachandran, S. and R. Pande (2015). Why are Indian children so short? Unpublished Manuscript.

Jelenkovic, A., R. Sund, Y.-M. Hur, Y. Yokoyama, J. Hjelmborg, and others (2016). Genetic and environmental influences on height from infancy to early adulthood: An individual-based pooled analysis of 45 twin cohorts. Scientific Reports 6(28496).

Kim, Y., B. Sikoki, J. Strauss, and F. Witoelar (2015). Intergenerational correlations of health among older adults: Empirical evidence from Indonesia. The Journal of the Economics of Ageing 6, 44-56.

Li, Q. and L. An (2015). Intergenerational health consequences of the 1959-1961 Great Famine on children in rural China. Economics and Human Biology 18, 27-40. 
Martorell, R. and J.-P. Habicht (1986). Growth in early childhood in developing countries. In F. Falkner and J. M. Tanner (Eds.), Human growth: a comprehensive treatise, Volume 3. New York: Plenum Press.

Martorell, R., L. Kettel Khan, and D. Schroeder (1994). Reversibility of stunting: epidemiological findings in children from developing countries. European journal of clinical nutrition 48(1), 45-57.

McLean, E., M. Cogswell, I. Egli, D. Wojdyla, and B. De Benoist (2009). Worldwide prevalence of anaemia, WHO Vitamin and Mineral Nutrition Information System, 1993-2005. Public health nutrition 12(4), $444-454$.

Panagariya, A. (2013). Does India really suffer from worse child malnutrition than sub-Saharan Africa? Economic and Political Weekly 48(18), 98-111.

Proos, L. A. (2009). Growth \& development of Indian children adopted in Sweden. Indian Journal of Medical Research 130(5), 646-650.

Proos, L. A., Y. Hofvander, K. Wennqvist, and T. Tuvemo (1992). A longitudinal study on anthropometric and clinical development of Indian children adopted in Sweden. II. Growth, morbidity and development during two years after arrival in Sweden. Upsala Journal of Medical Sciences 97(1), 93-106.

Ramalingaswami, V., U. Jonsson, and J. Rohde (1996). The Asian enigma. In Progress of Nations. New York: United Nation's Children Fund.

Riosmena, F., R. Wong, and A. Palloni (2013). Migration selection, protection, and acculturation in health: A binational perspective on older adults. Demography 50(3), 1039-1064.

Rubalcava, L., G. Teruel, D. Thomas, and N. Goldman (2008). The healthy migrant effect: new findings from the Mexican Family Life Survey. American Journal of Public Health 98(1), 78-84.

Schroeder, D., R. Martorell, J. Rivera, M. Ruel, and J.-P. Habicht (1995). Age differences in the impact of nutritional supplementation on growth. Journal of Nutrition 125, 105159.

Sinha, D. (2015). Maternal and child health. Inching ahead, miles to go. Economic and Political Weekly 50(49), 16-19.

Spears, D. (2012). How much international variation in child height can sanitation explain? Working Paper, Princeton University.

Steckel, R. H. (1995). Stature and the standard of living. Journal of Economic Literature 33(December), 1903-1940.

Strauss, J. and D. Thomas (1998). Health, nutrition, and economic development. Journal of Economic Literature 36(2), 766-817.

Strauss, J. and D. Thomas (2008). Health over the life course. In T. P. Schultz and J. Strauss (Eds.), Handbook of Development Economics, Volume IV, Chapter 54. Amsterdam: Elsevier Science.

Tarozzi, A. (2008). Growth reference charts and the nutritional status of Indian children. Economics and Human Biology 6(3), 455-468.

Tarozzi, A. (2012). Some facts about boy versus girl health indicators in India: 1992-2005. CESifo Economic Studies 58(2), 296-321.

van den Berg, G., P. Lundborg, P. Nystedt, and D.-O. Rooth (2014). Critical periods during childhood and adolescence. Journal of the European Economic Association 12(6), 1521-1557.

Wood, A. R., T. Esko, J. Yang, S. Vedantam, T. H. Pers, S. Gustafsson, A. Y. Chu, and others (2014). Defining the role of common variation in the genomic and biological architecture of adult human height. Nature Genetics 46(11), 1173-1186. 
World Health Organization (2006). WHO child growth standards length/height-for-age, weight-for-age, weight-for-length, weight-for-height and body mass index-for-age: Methods and development. Geneva. World Health Organization. 
(A) - Men

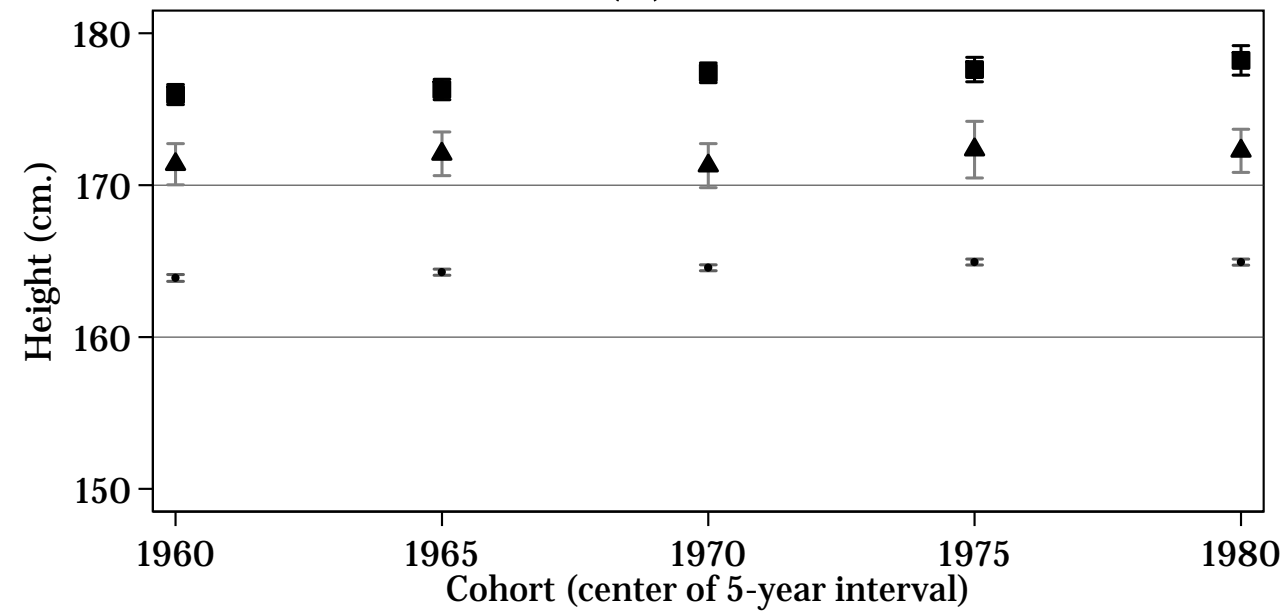

- India \ England Indians - England Whites

(B) - Women



- India \ England Indians - England Whites

Figure 1: Adult heights

Source: Authors' estimations from NFHS-3 (2005-06), HSE 1999 and HSE 2004. Each point represents the average height of individuals, labeled as in the legend, whose reported year of birth was included in the 5-year interval centered on the year labeled in the horizontal axis. Each point estimate is shown included within its $95 \%$ confidence interval. For men (panel A) sample sizes are 44,467 (NFHS-3), 548 (HSE, Indians) and 2,515 (HSE, Whites), while for women (panel B) they are respectively 80,346, 662 and 3,204. All estimates use sample weights, and confidence bands take into account the clustered design of each survey. 
(A) - Males

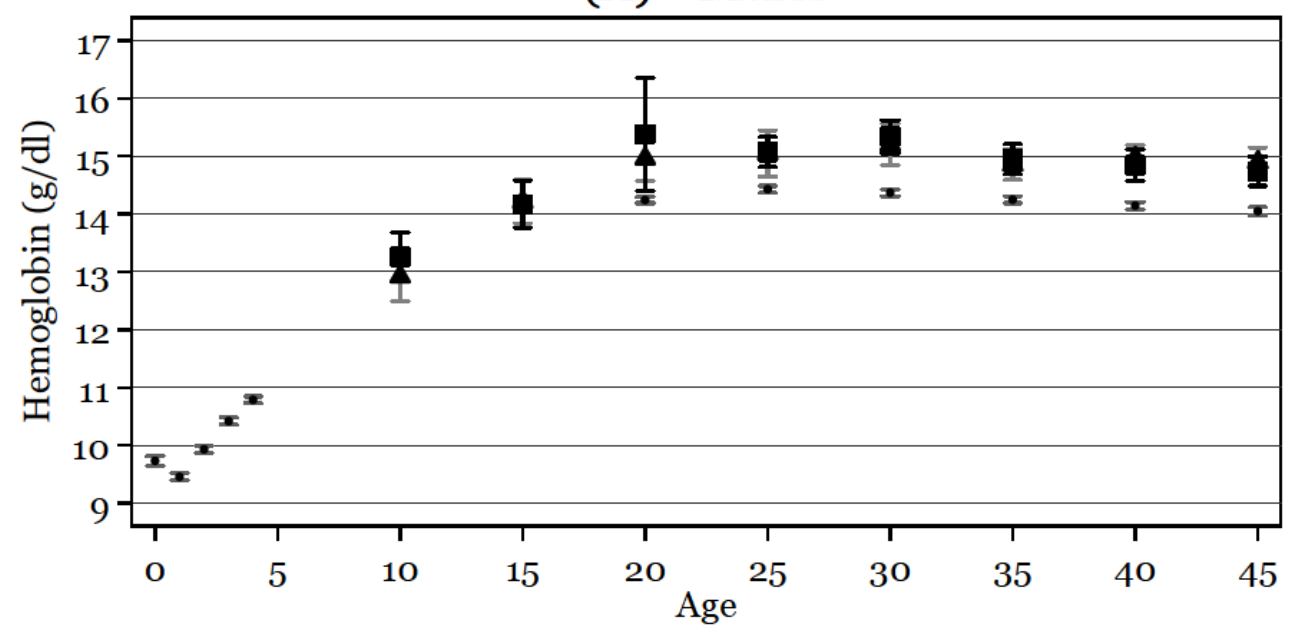

- India $\Delta$ England Indians $\square$ England Whites

(B) - Females

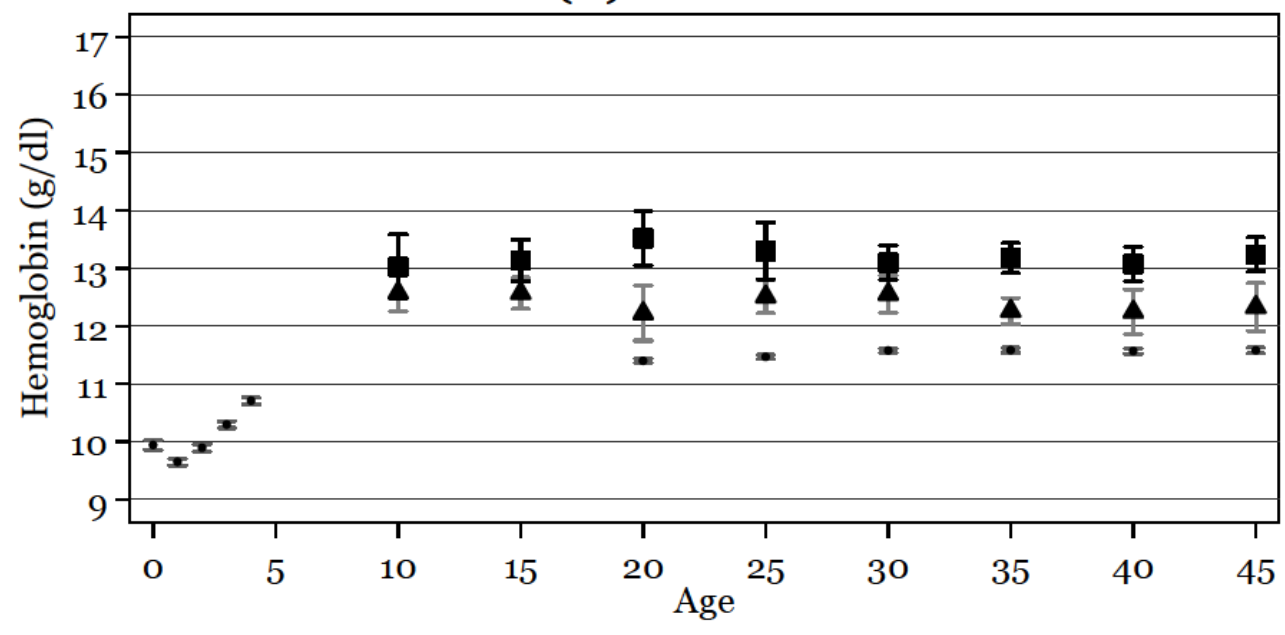

- India $\Delta$ England Indians $\square$ England Whites

Figure 2: Hemoglobin

Source: Authors' estimations from NFHS-3, HSE 1999 and HSE 2004. Each point represents average hemoglobin levels (in grams per deciliter of blood) for the specified age group. Children 0-4 were only tested in NFHS-3, and the sample includes 18,051 girls and 19,950 boys. For older persons each estimate uses information for individuals whose age was included in the 5-year interval centered on the age indicated in the label. The HSE only measured Hb for persons older than 10, while NFHS-3 only tested adult women 15-49 and a random subset of men 15-54. The sample size for 'Whites' in HSE is relatively small because not all individuals older that 10 were tested, see Section 3 for details. For males (excluding children 0-4, panel A) sample sizes are 53,495 (NFHS), 445 (HSE, Indians) and 369 (HSE, Whites), while for females (panel B, excluding 0-4 girls) they are respectively 99,494, 447 and 468. Point estimates use sample weights and are shown included within their $95 \%$ confidence interval that take into account the clustered design of each survey. 
(A) - Boys

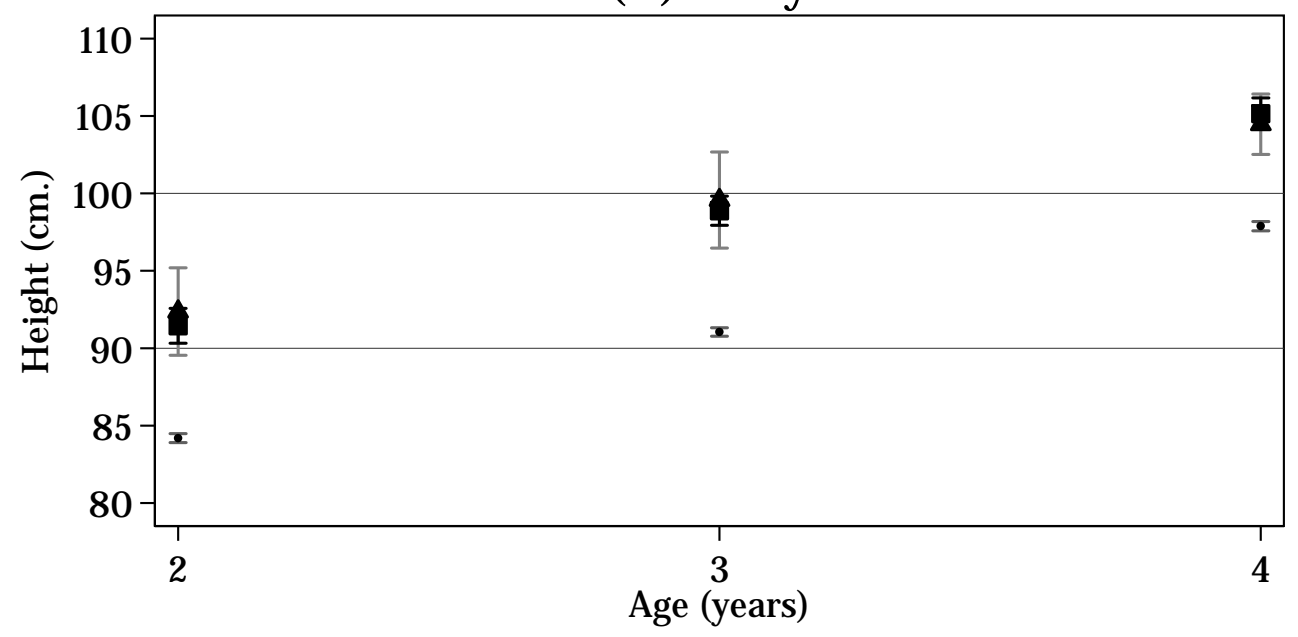

- India $\Delta$ England Indians - England Whites

(B) - Girls

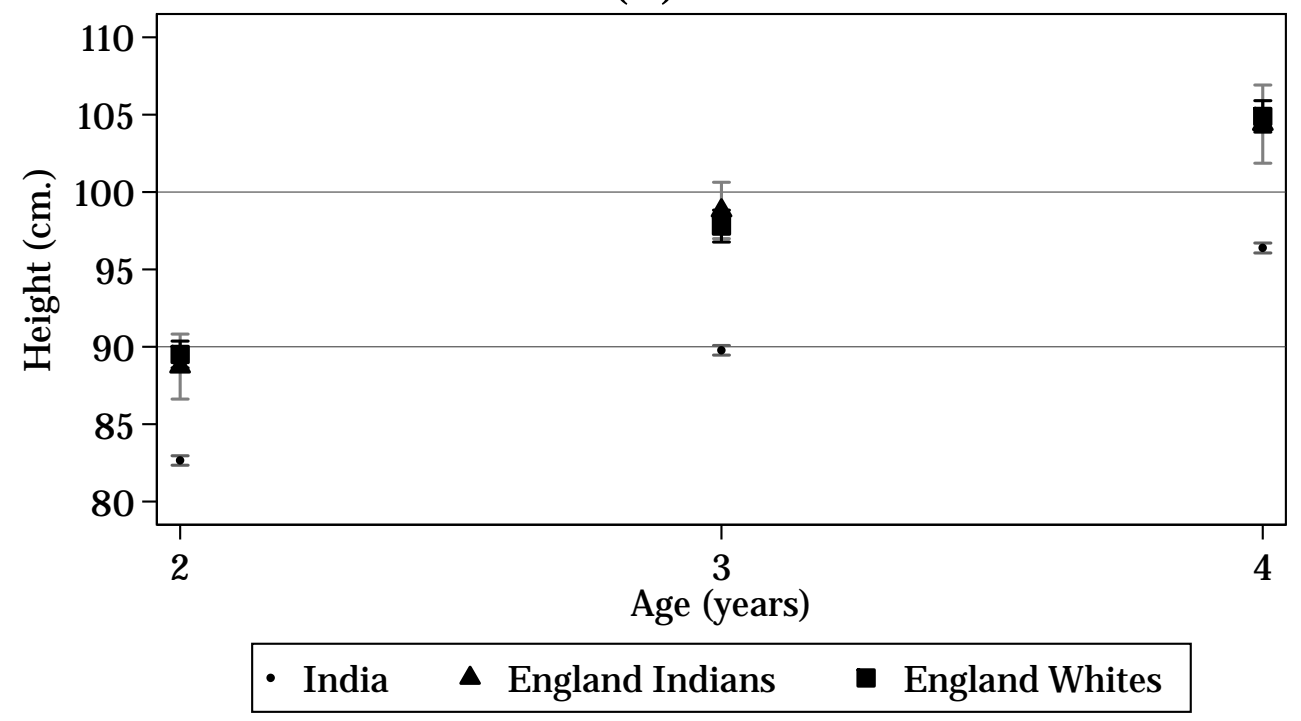

Figure 3: Children heights

Source: Authors' estimations from NFHS-3 (2005-06), HSE 1999 and HSE 2004. Each point represents the average height of children, by age. Point estimates are shown included within their $95 \%$ confidence interval. For boys (panel A) sample sizes are 14,760 (NFHS-3), 77 (HSE, Indians) and 326 (HSE, Whites), while for girls (panel B) they are respectively 13,527, 65 and 328. All estimates use sample weights. Confidence bands take into account the clustered design of each survey. See Table 2 for the detailed results. 
(A) - Boys

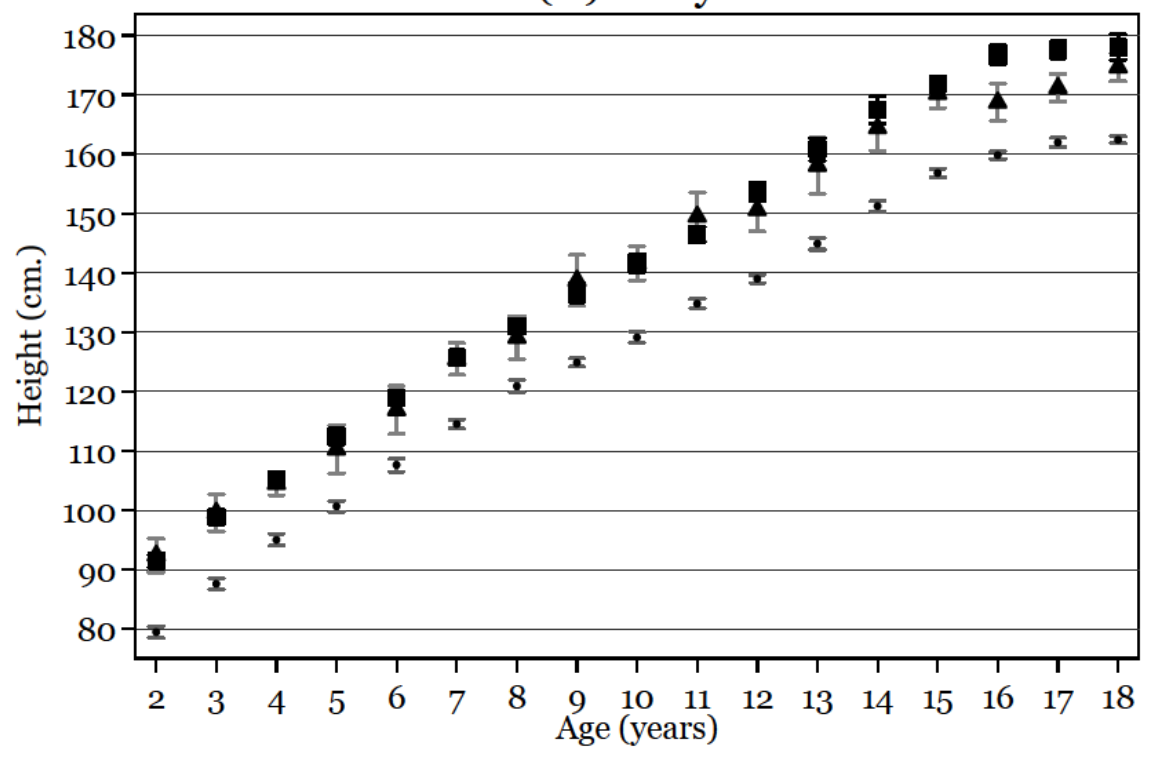

- India $\Delta$ UK Indians $\boldsymbol{\text { UK Whites }}$

(B) - Girls

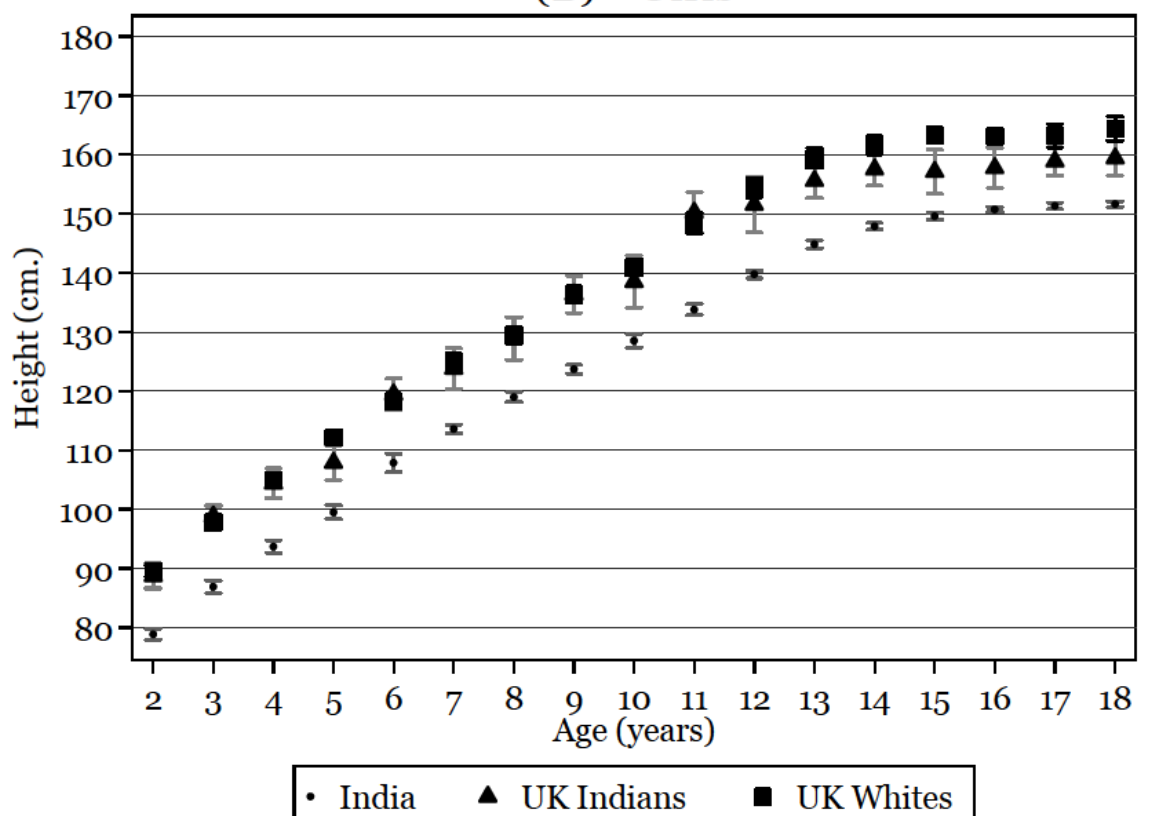

Figure 4: Children heights

Source: Authors' estimations from IHDS-2 (2011-12), HSE 1999 and HSE 2004. Each point represents the average height of children, by age (2-18). Point estimates are shown included within their $95 \%$ confidence interval. For boys (panel A) sample sizes are 26550 (IHDS), 458 (HSE, Indians) and 1837 (HSE, Whites), while for girls (panel B) they are respectively 25667, 388 and 1837. All estimates use sample weights. Confidence bands take into account the clustered design of each survey. 


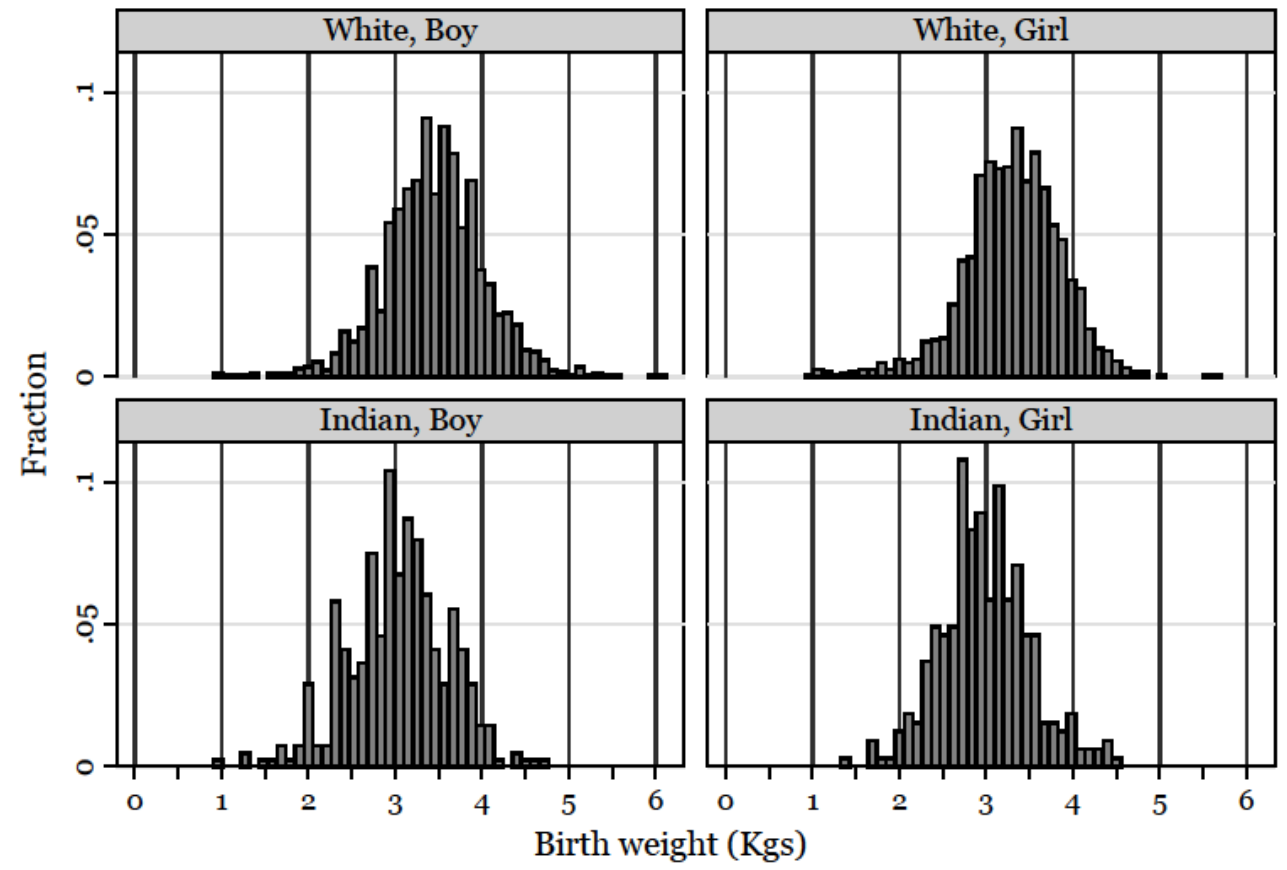

Figure 5: Histograms of Birth Weight

Source: Authors' estimations from HSE 1999 and HSE 2004. The sample includes children age 2-15 in HSE 1999 and 0-15 in HSE 2004. 
Table 1: Summary Statistics

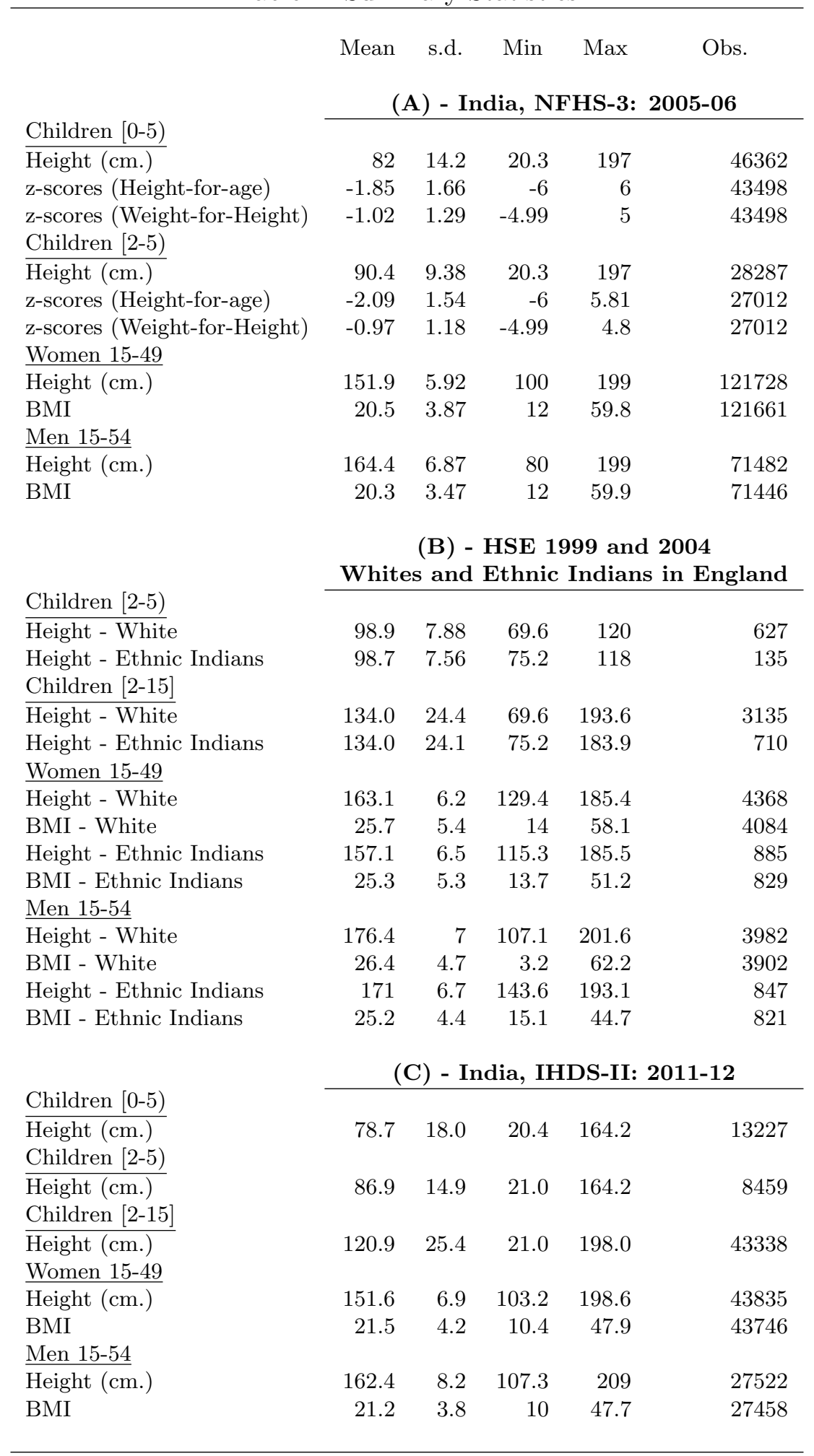

Source: Authors' estimations from NFHS-3 (2005-06), HSE 1999 and HSE 2004, and IHDS-II (2011-12). All estimates are calculated using sampling weights, see Appendix A.2 for details. The z-scores for children are those in the original data set, calculated using the 2006 WHO growth charts as references (World Health Organization 2006). For adults, Body Mass Index (BMI) is calculated as weight in Kgs. divided by the square of height (in meters). For IHDS-II, weight and height are set to missing when the age-gender specific standardized measure if larger than five in absolute value or, for children, if the measure is below (above) the minimum (maximum) in the corresponding demographic group in NFHS-3. 
Table 2: Children, HSE vs NFHS-3

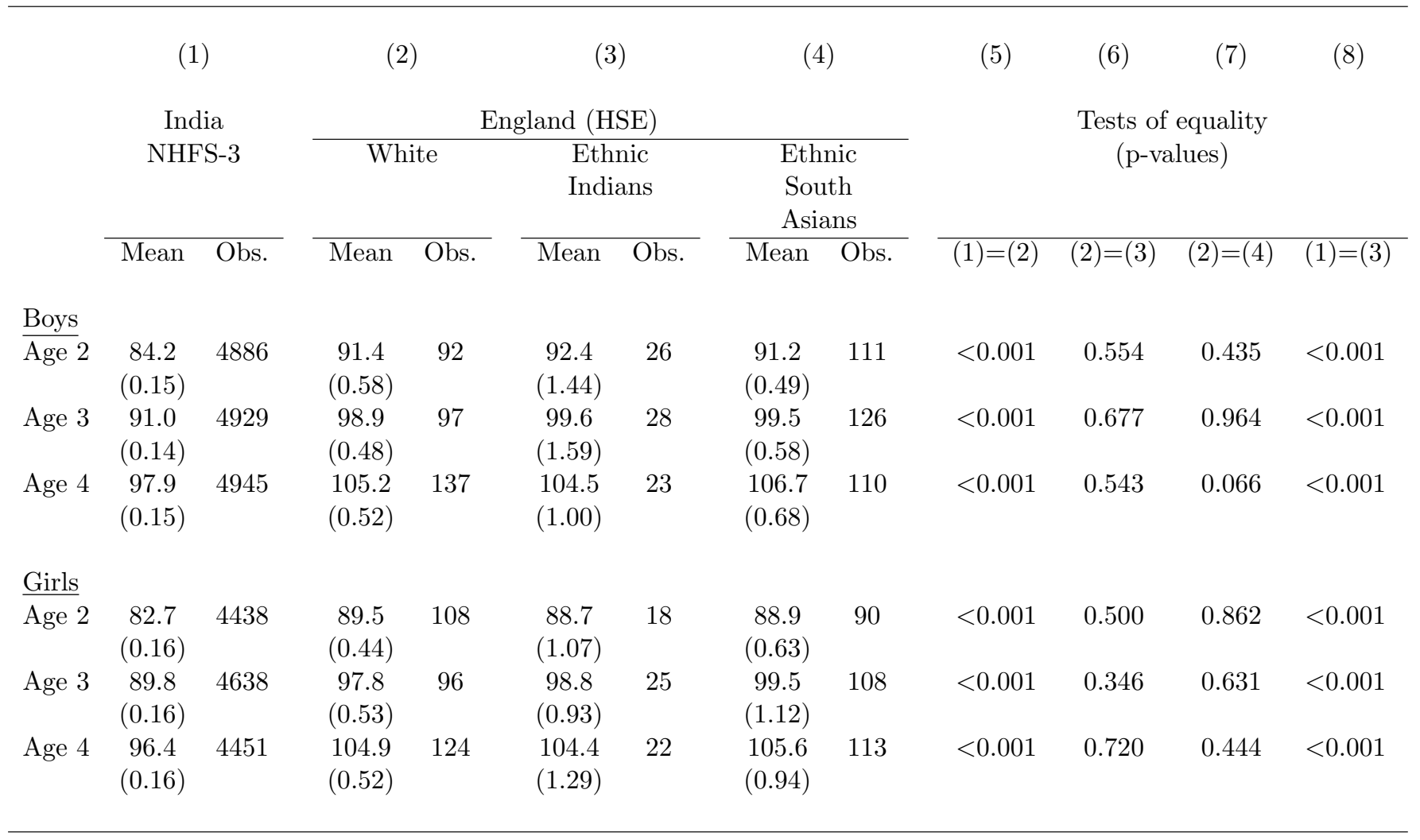

Source: Authors' estimations from NFHS-3 (2005-06), HSE 1999 and HSE 2004. The means and (in parentheses) standard errors in columns 1-3 are the same used to construct Figure 3. The estimates in column 4 are estimated using children in immigrant families from India, Pakistan and Bangladesh. In columns 5-8 we report p-values for tests of equality in means between the two groups specified in the column header. All estimates are calculated using survey-specific sampling weights and standard errors and tests allow for correlation within the primary stage unit of the survey. 
Table 3: Children, HSE vs IHDS-II

\begin{tabular}{|c|c|c|c|c|c|c|c|c|c|c|c|}
\hline \multirow{4}{*}{$\begin{array}{r}\text { Age } \\
\text { Years) }\end{array}$} & (1) & $(2)$ & $(3)$ & $(4)$ & (5) & $(6)$ & (7) & (8) & $(9)$ & (10) & (11) \\
\hline & \multirow{2}{*}{\multicolumn{3}{|c|}{ IHDS-II }} & \multicolumn{6}{|c|}{ Health Survey of England } & \multicolumn{2}{|c|}{ Differences } \\
\hline & & & & \multicolumn{3}{|c|}{ Ethnic Indians } & \multicolumn{3}{|c|}{ Whites } & $(4)-(1)$ & $(7)-(4)$ \\
\hline & $\begin{array}{l}\text { Height } \\
(\mathrm{cm} .)\end{array}$ & s.e. & Obs. & $\begin{array}{l}\text { Height } \\
(\mathrm{cm}\end{array}$ & s.e. & Obs. & $\begin{array}{l}\text { Height } \\
(\mathrm{cm}\end{array}$ & s.e. & Obs. & & \\
\hline \multicolumn{12}{|c|}{ Boys } \\
\hline 2 & 79.4 & 0.51 & 1447 & 92.6 & 1.48 & 24 & 91.4 & 0.60 & 88 & 13.2 & -1.2 \\
\hline 3 & 87.6 & 0.46 & 1493 & 99.6 & 1.60 & 27 & 98.8 & 0.48 & 95 & 12.0 & -0.8 \\
\hline 4 & 95.0 & 0.50 & 1441 & 104.4 & 1.07 & 21 & 105.2 & 0.53 & 133 & 9.4 & 0.8 \\
\hline 5 & 100.6 & 0.47 & 1614 & 109.7 & 2.23 & 24 & 112.4 & 0.70 & 102 & 9.1 & 2.6 \\
\hline 6 & 107.6 & 0.56 & 1564 & 116.6 & 2.20 & 21 & 118.9 & 0.46 & 125 & 9.0 & 2.2 \\
\hline 7 & 114.5 & 0.40 & 1768 & 125.3 & 1.38 & 26 & 125.7 & 0.65 & 111 & 10.8 & 0.4 \\
\hline 8 & 120.9 & 0.52 & 1545 & 129.1 & 1.89 & 25 & 131.0 & 0.60 & 127 & 8.2 & 1.9 \\
\hline 9 & 124.9 & 0.37 & 1449 & 138.7 & 2.23 & 32 & 136.6 & 0.84 & 125 & 13.8 & -2.1 \\
\hline 10 & 129.1 & 0.46 & 1853 & 141.5 & 1.50 & 30 & 141.8 & 0.81 & 114 & 12.4 & 0.3 \\
\hline 11 & 134.8 & 0.39 & 1466 & 150.3 & 1.89 & 22 & 146.4 & 0.70 & 116 & 15.5 & -3.9 \\
\hline 12 & 139.0 & 0.34 & 2024 & 150.6 & 1.88 & 24 & 153.4 & 0.79 & 135 & 11.6 & 2.8 \\
\hline 13 & 144.9 & 0.52 & 1543 & 157.9 & 2.51 & 26 & 160.9 & 0.97 & 112 & 13.0 & 2.9 \\
\hline 14 & 151.2 & 0.44 & 1721 & 164.1 & 2.04 & 32 & 167.1 & 1.22 & 101 & 12.9 & 3.0 \\
\hline 15 & 156.8 & 0.38 & 1429 & 170.4 & 1.24 & 30 & 171.7 & 0.68 & 101 & 13.5 & 1.4 \\
\hline 16 & 159.8 & 0.32 & 1494 & 168.7 & 1.59 & 27 & 176.9 & 0.71 & 90 & 8.9 & 8.2 \\
\hline 17 & 162.0 & 0.39 & 1433 & 170.9 & 1.02 & 18 & 177.7 & 0.76 & 79 & 9.0 & 6.7 \\
\hline 18 & 162.4 & 0.30 & 1218 & 174.7 & 1.35 & 14 & 177.9 & 1.11 & 71 & 12.3 & 3.2 \\
\hline \multicolumn{12}{|l|}{ Girls } \\
\hline 2 & 78.9 & 0.48 & 1339 & 88.6 & 1.08 & 17 & 89.6 & 0.44 & 107 & 9.8 & 1.0 \\
\hline 3 & 86.9 & 0.55 & 1402 & 99.3 & 0.81 & 24 & 97.8 & 0.53 & 96 & 12.4 & -1.5 \\
\hline 4 & 93.7 & 0.55 & 1337 & 104.4 & 1.44 & 17 & 104.9 & 0.53 & 118 & 10.7 & 0.5 \\
\hline 5 & 99.5 & 0.59 & 1389 & 107.9 & 1.52 & 22 & 112.2 & 0.60 & 102 & 8.4 & 4.3 \\
\hline 6 & 107.9 & 0.80 & 1373 & 119.2 & 1.34 & 18 & 118.2 & 0.63 & 107 & 11.3 & -1.0 \\
\hline 7 & 113.6 & 0.37 & 1650 & 123.9 & 1.79 & 27 & 124.8 & 0.74 & 101 & 10.4 & 0.9 \\
\hline 8 & 119.0 & 0.43 & 1430 & 128.7 & 1.92 & 25 & 129.4 & 0.67 & 119 & 9.7 & 0.7 \\
\hline 9 & 123.7 & 0.39 & 1320 & 136.7 & 1.50 & 23 & 136.3 & 0.69 & 96 & 13.0 & -0.4 \\
\hline 10 & 128.5 & 0.57 & 1746 & 138.5 & 2.25 & 23 & 141.1 & 0.73 & 109 & 10.0 & 2.6 \\
\hline 11 & 133.8 & 0.47 & 1294 & 150.2 & 1.76 & 26 & 148.4 & 0.90 & 105 & 16.5 & -1.9 \\
\hline 12 & 139.7 & 0.34 & 1869 & 151.5 & 2.40 & 21 & 154.7 & 0.86 & 98 & 11.8 & 3.2 \\
\hline 13 & 144.8 & 0.34 & 1586 & 155.6 & 1.51 & 22 & 159.4 & 0.87 & 101 & 10.8 & 3.8 \\
\hline 14 & 147.9 & 0.28 & 1697 & 157.5 & 1.43 & 32 & 161.5 & 0.81 & 95 & 9.7 & 4.0 \\
\hline 15 & 149.6 & 0.30 & 1549 & 157.1 & 1.91 & 17 & 163.2 & 0.55 & 126 & 7.5 & 6.1 \\
\hline 16 & 150.7 & 0.22 & 1602 & 158.3 & 1.87 & 19 & 163.2 & 0.66 & 113 & 7.6 & 4.8 \\
\hline 17 & 151.3 & 0.27 & 1536 & 159.8 & 1.43 & 14 & 163.1 & 1.03 & 93 & 8.5 & 3.4 \\
\hline 18 & 151.6 & 0.25 & 1504 & 160.2 & 1.70 & 13 & 164.6 & 1.06 & 93 & 8.5 & 4.4 \\
\hline
\end{tabular}

Source: Authors' estimations from IHDS-II (2011-12), HSE 1999 and HSE 2004. All estimates are calculated using survey-specific sampling weights and standard errors and tests allow for correlation within the primary stage unit of the survey. Height in measured in centimeters. In column (10) we calculate the differences between the average height of ethnic Indians in England (column 4) and Indian children in India (1), while in column (11) we calculate differences between Whites (7) and ethnic Indians (4) in England. The number of observations for ethnic Indian children 2 to 4 are not identical to those in Table 2 because here we only include children born in England, while Table 2 also includes 12 children who were born elsewhere. 
Table 4: Intergenerational Transmission of Height, HSE vs NFHS-3 (Age 2-4)

Source: authors' estimations from NFHS-3, HSE 1999 and HSE 2004 (OLS regressions). HSE data include only children of Indian ethnicity. Standard errors (in parentheses) are clustered at the primary sampling unit level. The sample includes children aged 2 and above but below 5 . In columns 1 and 4 we include information on children with non-missing mother's height, but in columns 2-3 and 5-6 we drop observations for which paternal height is missing. All coefficients are significant at the $1 \%$ level.

Table 5: Intergenerational Transmission of Height, HSE vs IHDS-II (Age 2-18)

\begin{tabular}{|c|c|c|c|c|c|c|}
\hline & $(1)$ & $\begin{array}{c}(2) \\
\text { Girls }\end{array}$ & (3) & (4) & $\begin{array}{c}(5) \\
\text { Boys }\end{array}$ & (6) \\
\hline England & $\begin{array}{c}0.0793 \\
(0.00391)\end{array}$ & $\begin{array}{c}0.0863 \\
(0.00511)\end{array}$ & $\begin{array}{c}0.0752 \\
(0.00510)\end{array}$ & $\begin{array}{c}0.0838 \\
(0.00332)\end{array}$ & $\begin{array}{c}0.0894 \\
(0.00406)\end{array}$ & $\begin{array}{c}0.0776 \\
(0.00422)\end{array}$ \\
\hline Log(Father's height) & & & $\begin{array}{c}0.322 \\
(0.0416)\end{array}$ & & & $\begin{array}{c}0.368 \\
(0.0390)\end{array}$ \\
\hline Log(Mother's height) & $\begin{array}{c}0.379 \\
(0.0315)\end{array}$ & $\begin{array}{c}0.298 \\
(0.0508)\end{array}$ & $\begin{array}{c}0.205 \\
(0.0510)\end{array}$ & $\begin{array}{c}0.382 \\
(0.0295)\end{array}$ & $\begin{array}{c}0.345 \\
(0.0406)\end{array}$ & $\begin{array}{c}0.241 \\
(0.0415)\end{array}$ \\
\hline Constant & $\begin{array}{c}2.453 \\
(0.159)\end{array}$ & $\begin{array}{c}2.837 \\
(0.255)\end{array}$ & $\begin{array}{c}1.661 \\
(0.313)\end{array}$ & $\begin{array}{l}2.445 \\
(0.148)\end{array}$ & $\begin{array}{c}2.630 \\
(0.204)\end{array}$ & $\begin{array}{c}1.283 \\
(0.250)\end{array}$ \\
\hline Age (in years) & Yes & Yes & Yes & Yes & Yes & Yes \\
\hline Observations & 22,277 & 10,852 & 10,852 & 23,670 & 11,772 & 11,772 \\
\hline R-squared & 0.766 & 0.737 & 0.740 & 0.779 & 0.769 & 0.772 \\
\hline
\end{tabular}

Source: authors' estimations from IHDS-II, HSE 1999 and HSE 2004 (OLS regressions). HSE data include only children of Indian ethnicity. Standard errors (in parentheses) are clustered at the primary sampling unit level. The sample includes children aged 2-18, and all regressions also include age dummies. In columns 1 and 4 we include information on children with non-missing mother's height, but in columns 2-3 and 5-6 we drop observations for which paternal height is missing. All coefficients are significant at the $1 \%$ level. 
Table 6: Intergenerational Transmission of Height, HSE vs IHDS-II (Age 2-4)

\begin{tabular}{|c|c|c|c|c|c|c|}
\hline & (1) & $\begin{array}{c}(2) \\
\text { Girls }\end{array}$ & (3) & (4) & $\begin{array}{c}(5) \\
\text { Boys }\end{array}$ & (6) \\
\hline England & $\begin{array}{c}0.129 \\
(0.00860)\end{array}$ & $\begin{array}{c}0.156 \\
(0.0118)\end{array}$ & $\begin{array}{c}0.133 \\
(0.0136)\end{array}$ & $\begin{array}{c}0.116 \\
(0.00895)\end{array}$ & $\begin{array}{c}0.130 \\
(0.0121)\end{array}$ & $\begin{array}{c}0.117 \\
(0.0126)\end{array}$ \\
\hline Log(Mother's height) & $\begin{array}{c}0.351 \\
(0.104)\end{array}$ & $\begin{array}{c}0.129 \\
(0.178)\end{array}$ & $\begin{array}{c}-0.0232 \\
(0.174)\end{array}$ & $\begin{array}{c}0.442 \\
(0.0925)\end{array}$ & $\begin{array}{c}0.391 \\
(0.144)\end{array}$ & $\begin{array}{l}0.256^{*} \\
(0.149)\end{array}$ \\
\hline Log(Father's height) & & & $\begin{array}{c}0.506 \\
(0.151)\end{array}$ & & & $\begin{array}{c}0.412 \\
(0.144)\end{array}$ \\
\hline Age 3 years & $\begin{array}{c}0.0957 \\
(0.0106)\end{array}$ & $\begin{array}{c}0.0938 \\
(0.0170)\end{array}$ & $\begin{array}{c}0.0942 \\
(0.0169)\end{array}$ & $\begin{array}{c}0.0975 \\
(0.0105)\end{array}$ & $\begin{array}{c}0.0872 \\
(0.0140)\end{array}$ & $\begin{array}{c}0.0873 \\
(0.0140)\end{array}$ \\
\hline Age 4 years & $\begin{array}{c}0.172 \\
(0.0101)\end{array}$ & $\begin{array}{c}0.167 \\
(0.0162)\end{array}$ & $\begin{array}{c}0.167 \\
(0.0161)\end{array}$ & $\begin{array}{c}0.182 \\
(0.00981)\end{array}$ & $\begin{array}{c}0.160 \\
(0.0131)\end{array}$ & $\begin{array}{c}0.160 \\
(0.0132)\end{array}$ \\
\hline Constant & $\begin{array}{c}2.592 \\
(0.522)\end{array}$ & $\begin{array}{c}3.684 \\
(0.892)\end{array}$ & $\begin{array}{l}1.870^{*} \\
(1.129)\end{array}$ & $\begin{array}{c}2.141 \\
(0.465)\end{array}$ & $\begin{array}{c}2.402 \\
(0.721)\end{array}$ & $\begin{array}{c}0.978 \\
(0.898)\end{array}$ \\
\hline Observations & 3,825 & 1,686 & 1,686 & 4,182 & 1,881 & 1,881 \\
\hline R-squared & 0.128 & 0.098 & 0.107 & 0.157 & 0.121 & 0.127 \\
\hline
\end{tabular}

Source: authors' estimations from IHDS-II, HSE 1999 and HSE 2004 (OLS regressions). HSE data include only children of Indian ethnicity. Standard errors (in parentheses) are clustered at the primary sampling unit level. The sample includes children aged 2-4. In columns 1 and 4 we include information on children with non-missing mother's height, but in columns 2-3 and 5-6 we drop observations for which paternal height is missing.

Table 7: Differences in Child Height, Matching by Mother's Height

\begin{tabular}{cccc}
\multicolumn{2}{c}{$(1)$} & & $(2)$ \\
Boys & & Girls \\
\cline { 1 - 1 } Obs. & Difference & & Obs. Difference
\end{tabular}

\begin{tabular}{lcccc} 
& \multicolumn{4}{c}{ Matching on mother's height } \\
\cline { 2 - 5 } Age 2 & 16 & 4.17 & 12 & 6.73 \\
Age 3 & 21 & 6.24 & 12 & 5.51 \\
Age 4 & 17 & 3.04 & 18 & 3.41 \\
& \multicolumn{5}{l}{} \\
(B) & \multicolumn{4}{c}{ Matching on mother and father's height } \\
\cline { 2 - 5 } Age 2 & 13 & 3.77 & 12 & 5.1 \\
Age 3 & 21 & 4.61 & 12 & 3.34 \\
Age 4 & 16 & .562 & 18 & 3.13 \\
\end{tabular}

Source: Authors' estimations from HSE 1999, HSE 2004 and NFHS-3. The estimates in panel (A) show average differences in height between each child from HSE and all children in NFHS-3 whose mother was at least as tall as the index child. In panel (B) the comparison group is formed by children whose mother and father in NFHS-3 were at least as tall as the child's parents. 


\begin{tabular}{|c|c|c|c|}
\hline & $\begin{array}{l}\text { Birth weight } \\
\text { missing }\end{array}$ & $\begin{array}{l}\text { (2) } \\
\text { Birth weight } \\
(\mathrm{Kgs})\end{array}$ & $\begin{array}{l}\text { Birth weight } \\
\quad(\text { Kgs })\end{array}$ \\
\hline Constant (White boy) & $\begin{array}{c}0.123^{* * *} \\
(0.009)\end{array}$ & $\begin{array}{c}3.45^{* * *} \\
(0.015)\end{array}$ & $\begin{array}{c}3.45^{* * *} \\
(0.017)\end{array}$ \\
\hline White Girl & $\begin{array}{l}-0.006 \\
(0.011)\end{array}$ & $\begin{array}{c}-0.140^{* * *} \\
(0.019)\end{array}$ & $\begin{array}{c}-0.142^{* * *} \\
(0.022)\end{array}$ \\
\hline Ethnic Indian Boy & $\begin{array}{c}0.017 \\
(0.021)\end{array}$ & $\begin{array}{c}-0.414^{* * *} \\
(0.032)\end{array}$ & $\begin{array}{c}-0.402^{* * *} \\
(0.043)\end{array}$ \\
\hline Ethnic Indian Girl & $\begin{array}{c}0.015 \\
(0.021)\end{array}$ & $\begin{array}{c}-0.454^{* * *} \\
(0.036)\end{array}$ & $\begin{array}{c}-0.509^{* * *} \\
(0.054)\end{array}$ \\
\hline $\begin{array}{l}\text { Only children born in UK/Ireland } \\
\text { Obs. } \\
R^{2} \\
H_{0}: \text { White Girl = Ethnic Indian Girl: p-values }\end{array}$ & $\begin{array}{c}\text { No } \\
4606 \\
0.0006 \\
0.3091\end{array}$ & $\begin{array}{c}\text { No } \\
4037 \\
0.0692 \\
<0.0001\end{array}$ & $\begin{array}{c}\text { Yes } \\
3702 \\
0.0551 \\
<0.0001\end{array}$ \\
\hline
\end{tabular}

Source: Authors' estimations from HSE 1999 and HSE 2004. The column header indicates the dependent variable of an OLS regression. Standard errors (in parenthesis) are clustered at the primary sampling unit level. The sample includes children age 2-15 in HSE 1999 and 0-15 in HSE 2004. Asterisks denote statistical significance at the $1(* * *)$, $5(* *)$ or $10(*)$ percent level.

Table 9: Birth weight and parents' body size

\begin{tabular}{lccccc}
\hline & \multicolumn{5}{c}{ Dependent variable: $\log$ (birth weight) } \\
\cline { 2 - 6 } & $(1)$ & $(2)$ & $(3)$ & $(4)$ & $(5)$ \\
$\log$ (Mother's height) & $1.193^{* *}$ & $1.249^{* *}$ & $1.165^{* *}$ & $1.026^{* *}$ & $1.053^{* *}$ \\
& $(0.111)$ & $(0.144)$ & $(0.152)$ & $(0.161)$ & $(0.234)$ \\
$\log$ (Father's height) & & & $0.264^{*}$ & 0.078 & 0.246 \\
& & & $(0.129)$ & $(0.162)$ & $(0.245)$ \\
$\log$ (Mother's weight) & & & & $0.110^{* *}$ & $0.117^{* *}$ \\
& & & & $(0.028)$ & $(0.043)$ \\
$\log$ (Father's weight) & & & & $0.104^{* *}$ & 0.081 \\
& & & & $(0.036)$ & $(0.058)$ \\
Constant & $-4.880^{* *}$ & $-5.163^{* *}$ & $-6.098^{* *}$ & $-5.358^{* *}$ & $-6.291^{* *}$ \\
& $(0.566)$ & $(0.736)$ & $(0.847)$ & $(0.945)$ & $(1.536)$ \\
$R^{2}$ & & & & & \\
Obs. & 0.06 & 0.07 & 0.07 & 0.10 & 0.42 \\
& 3,872 & 2,222 & 2,222 & 2,100 & 2,100 \\
\hline
\end{tabular}

Source: Authors' estimations from HSE 1999 and HSE 2004. All estimates are from OLS regressions where the dependent variable is ( $\log )$ birth weight. In column 2 we exclude observations where father's height is missing. In column 5 we also include primary sampling unit fixed effects. Standard errors (in parenthesis) are clustered at the primary sampling unit level. The sample includes children age 2-15 in HSE 1999 and 0-15 in HSE 2004. Asterisks denote statistical significance at the $1(* * *), 5(* *)$ or $10\left(^{*}\right)$ percent level. 


\section{A Appendix}

\section{A.1 Adult Age Distribution in NFHS-3}

The histograms in Figure A.9 show the distribution of reported age (in years) in NFHS-3 for all adult members of sampled households. The histogram displays apparent peaks at multiples of five, a pattern that would almost surely not emerge if age were reported without error.

That the multi-peaked patterns are the results of reporting error is also confirmed when we look only at individuals who completed more than secondary school. Such individuals were highly unlikely not to know their age with precision, and indeed Figure A.10 confirms that the distribution of reported age for them show no apparent peaks.

\section{A.2 Sampling Weights}

All our key estimates are based on the comparison of average outcomes between individuals of different ethnicity and/or residence, and for this reason we use sampling weights when these are provided in the data, unless specified otherwise. In some cases several sets of sampling weights are provided, so in this sub-section we describe in detail our choices.

When using NFHS data, we use the 'national household weights', namely, the variable hv005 from the original individual-level data set IAHR52FL.dta.

The weighting scheme was different in HSE 1999 and HSE 2004. In pooling observations from both surveys we follow the procedure described by the UK Data Services. ${ }^{17}$ For 2004, we use the individual weights (wt_int) that take into account both non-response and non-contact as well as (only for the ethnic boost) the different probability of selection into the sample. For 1999, the use of weights is indicated only for children (because only up to two children per household, randomly determined, were measured) and for the ethnic boost sample (to account for varying probabilities of selection into the sample). Weights for households and adults from the general population were instead not deemed necessary as the sample was sufficiently close to be representative of the general population of England. The 1999 weights (ErrorWt) take into account the different probability of selection into the sample within each ethnic group.

The weights in each HSE are then re-scaled by dividing each by the survey-specific mean weight. In this way observations from each survey are given the same relevance, and the sum of the weights in each round (as well as in the pooled sample) is equal to the sum of the observations.

\footnotetext{
${ }^{17}$ See https://discover.ukdataservice.ac.uk/series/?sn=2000021\#poolingethnic, accessed February 9th, 2016.
} 
When we pool the sample from the HSE with the sample from either NFHS or IHDS (for instance, to produce the regression estimates in Tables 4 to 6), we similarly re-scale the weights in the Indian data by dividing them by their respective means. This way the sum of the weights in each data set is equal to the respective number of observations.

Of course, when estimating statistics that are specific to a single survey (e.g. average height for a given demographic and ethnic group in England, or in NHFS) the scale of the weights is irrelevant. Similarly, the key coefficient of interest in Tables 4 to 6 (that is, $\beta_{\text {England }}$ ) is barely affected by the re-scaling, given that such coefficient is identified by differences between data from two different surveys. However, the other slopes in these tables (which, in our preferred model, are not interacted with the "England" dummy) become closer to those estimated using only data from HSE when the scale of the weights in HSE become larger relative to the scale of the weights in the Indian data (and vice-versa). 


\section{(A) - Girls}

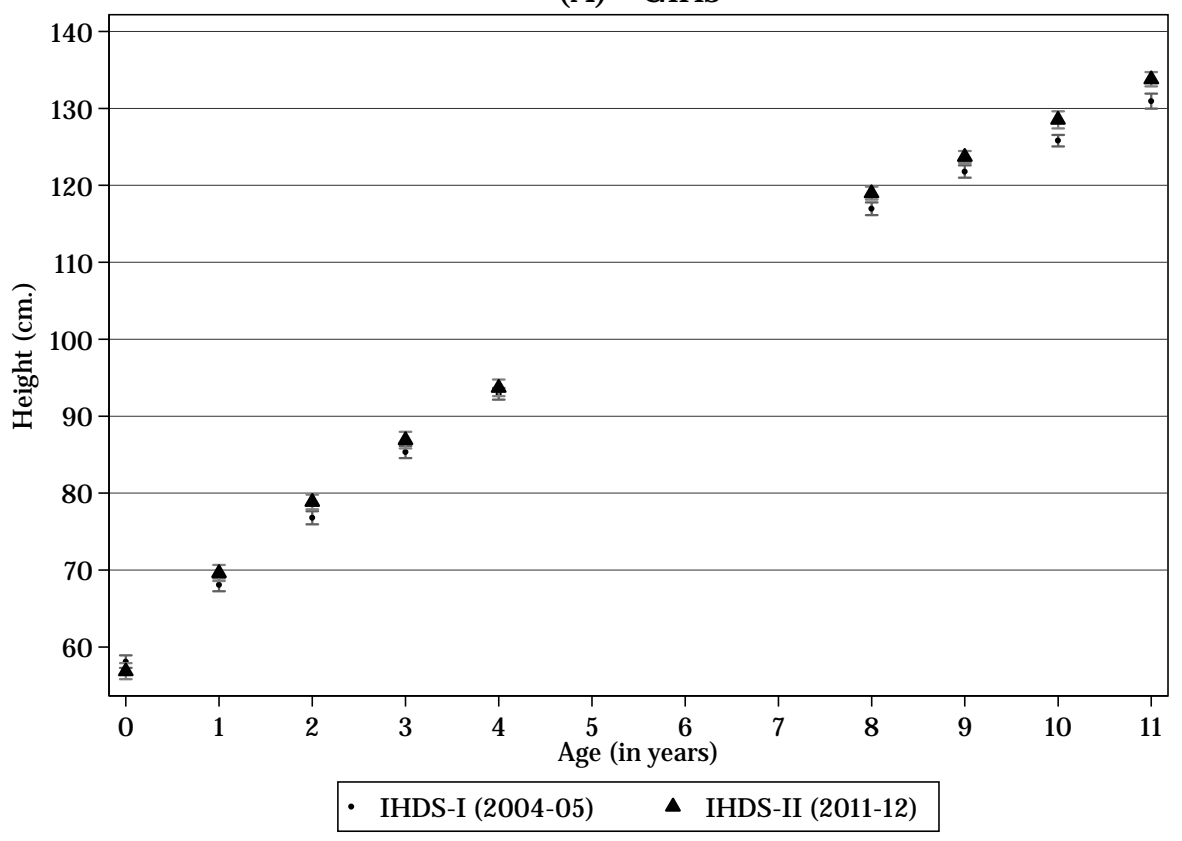

(B) - Boys

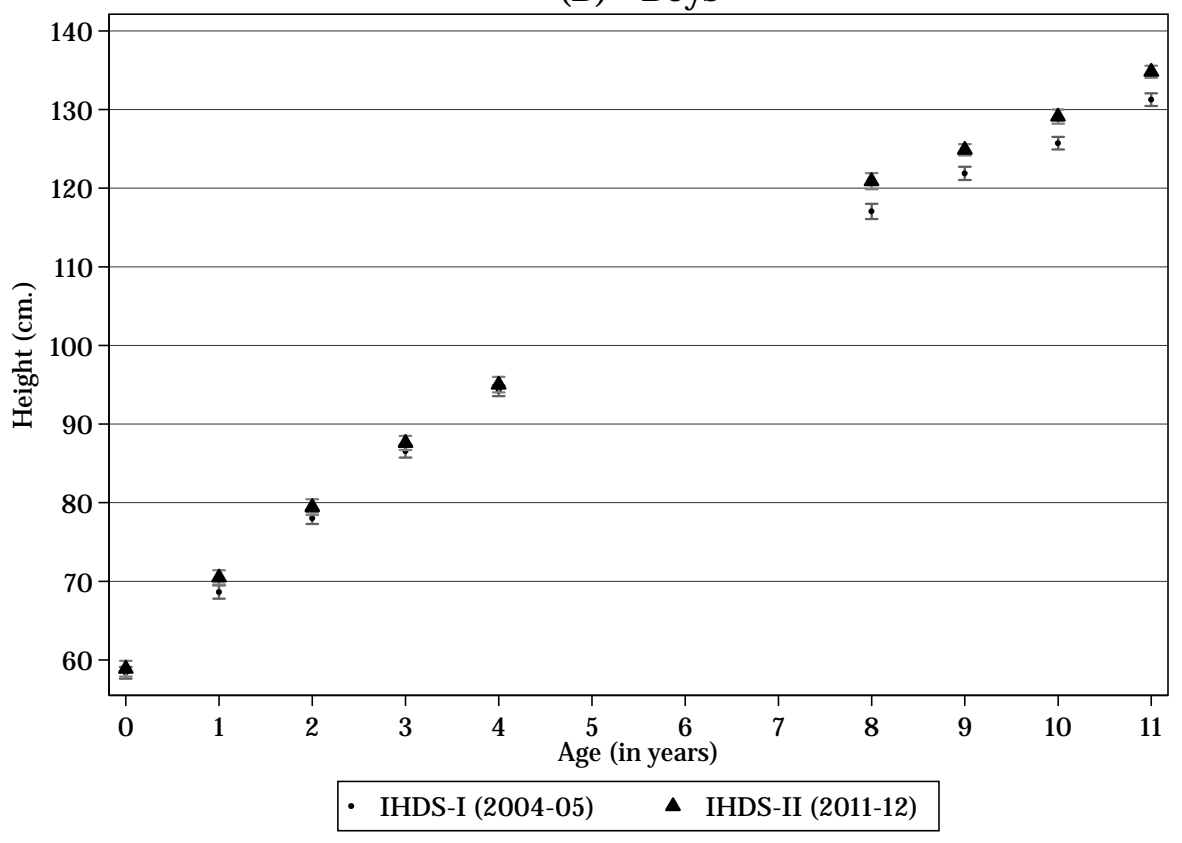

Figure A.6: Children height, IHDS-I vs IHDS-II

Source: Authors' estimations from IHDS-I (2004-05) and IHDS-2 (2011-12). Each point represents the average height of children by age (0-5 and 8-11 years old), with the $95 \%$ confidence interval. Panel A (boys) is based on 15,328 (IHDS-I) and 13,177 (IHDS-II) observations. Sample sizes for panel B (girls) are respectively 14,123 and 12,153. All estimates use sample weights, and standard errors are clustered at the primary sampling unit level (village or neighborhood). The point estimates for each age and genders, as well as the changes over time, are reported in Table A.12. 
(A) - Girls

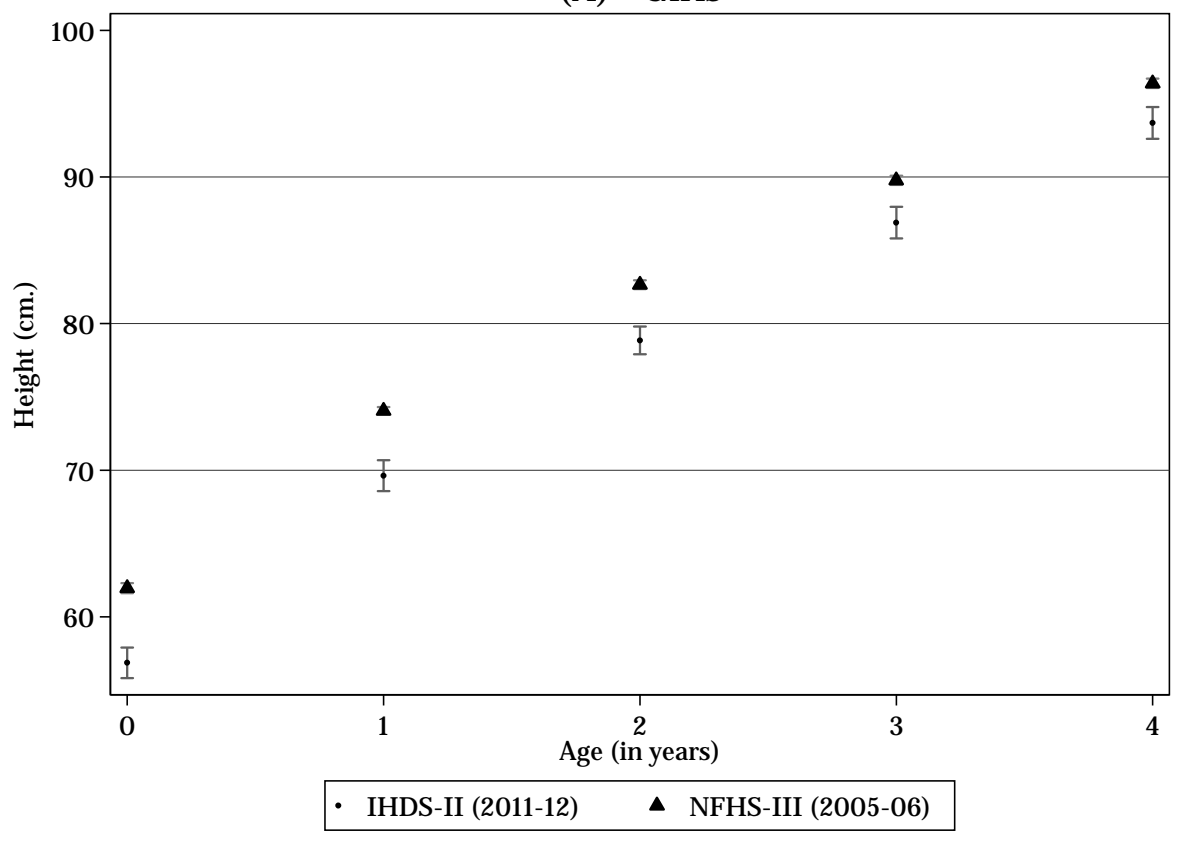

(B) - Boys

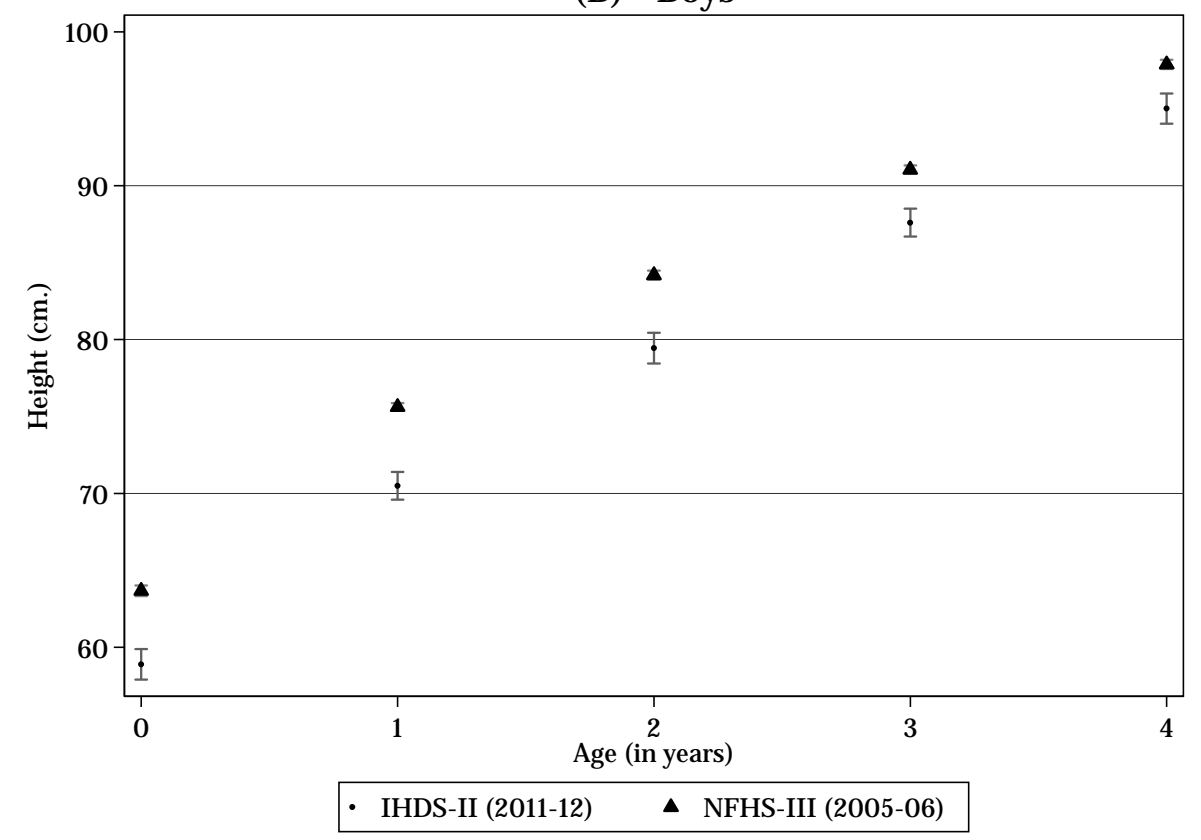

Figure A.7: Children Height, IHDS-II vs. NFHS-3

Source: Authors' estimations from IHDS-II (2011-12) and NFHS-3 (2005-06). Each point represents the average height of children by age, with the $95 \%$ confidence interval. All estimates use sample weights, and standard errors are clustered at the primary sampling unit level (village or neighborhood). 


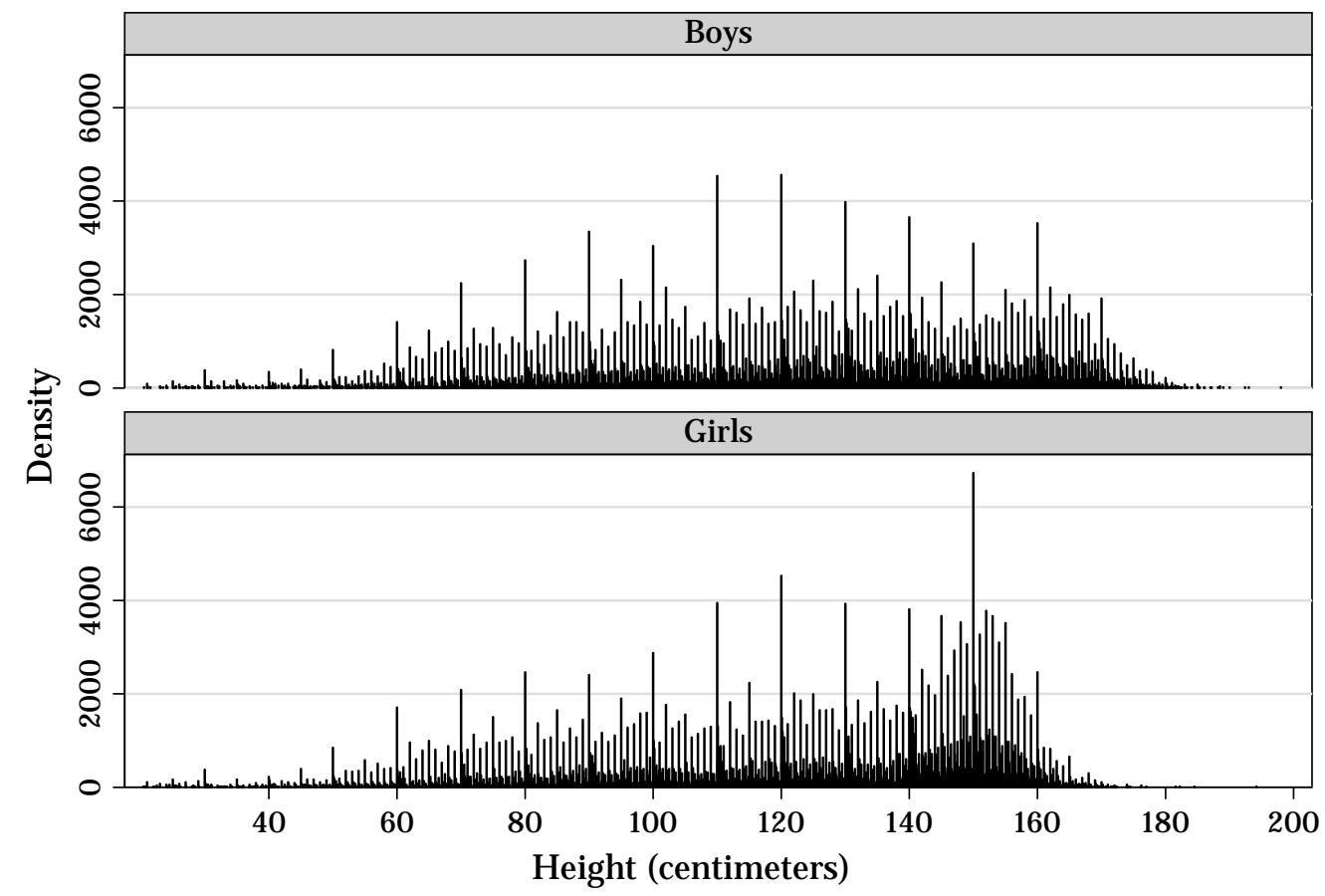

Figure A.8: Histograms of Height for Children, IHDS 2011-12

Source: Authors' calculations from IHDS-II, 2011-12. The histograms are constructed using height (in centimeters) for children $0-18$. The sample includes 28,985 boys and 27,908 girls. 


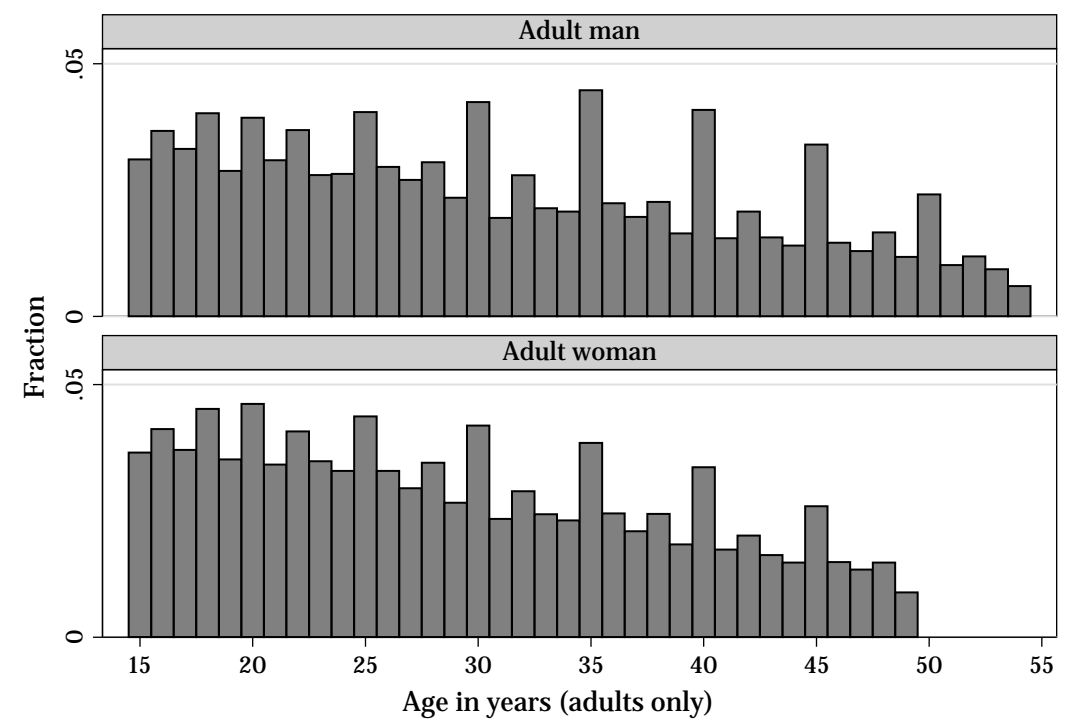

Figure A.9: Histograms of Reported Age for Adults, NFHS-3

Source: Authors' calculations from NFHS-3 data, 2005-06. The histograms are constructed using reported age for adults. The sample includes 89,834 men and 138,592 women.

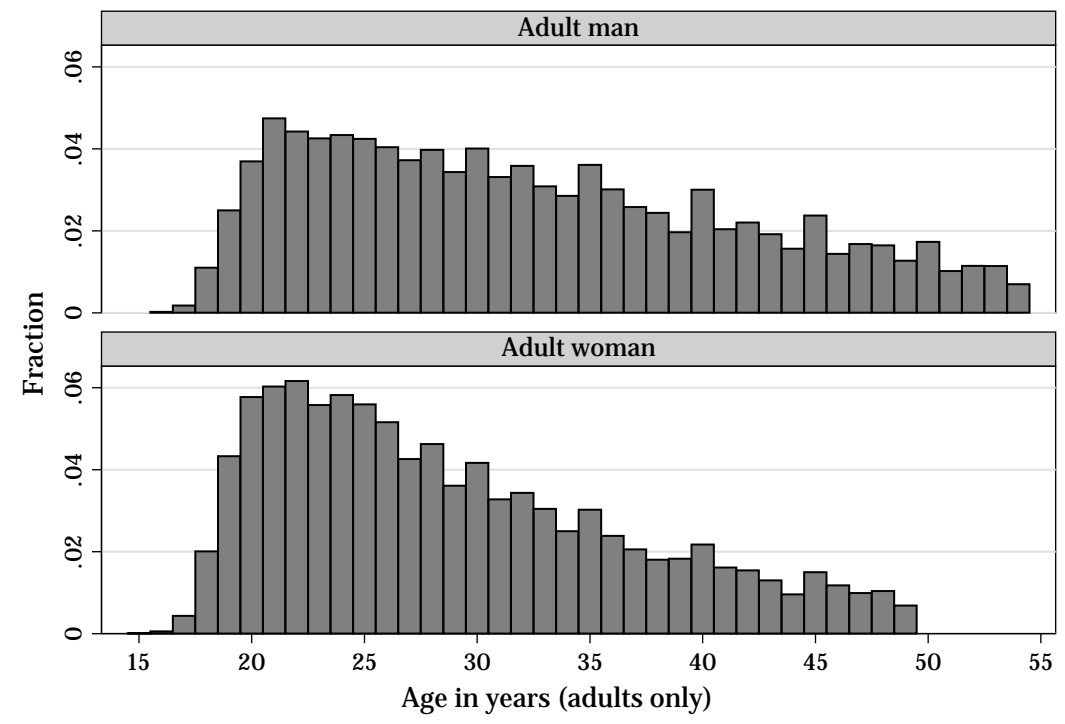

Figure A.10: Histograms of Reported Age for High-Education Adults, NFHS-3

Source: Authors' calculations from NFHS-3 data, 2005-06. The histograms are constructed using reported age for adults with schooling levels higher than secondary. The sample includes 14,102 men and 14,880 women. 


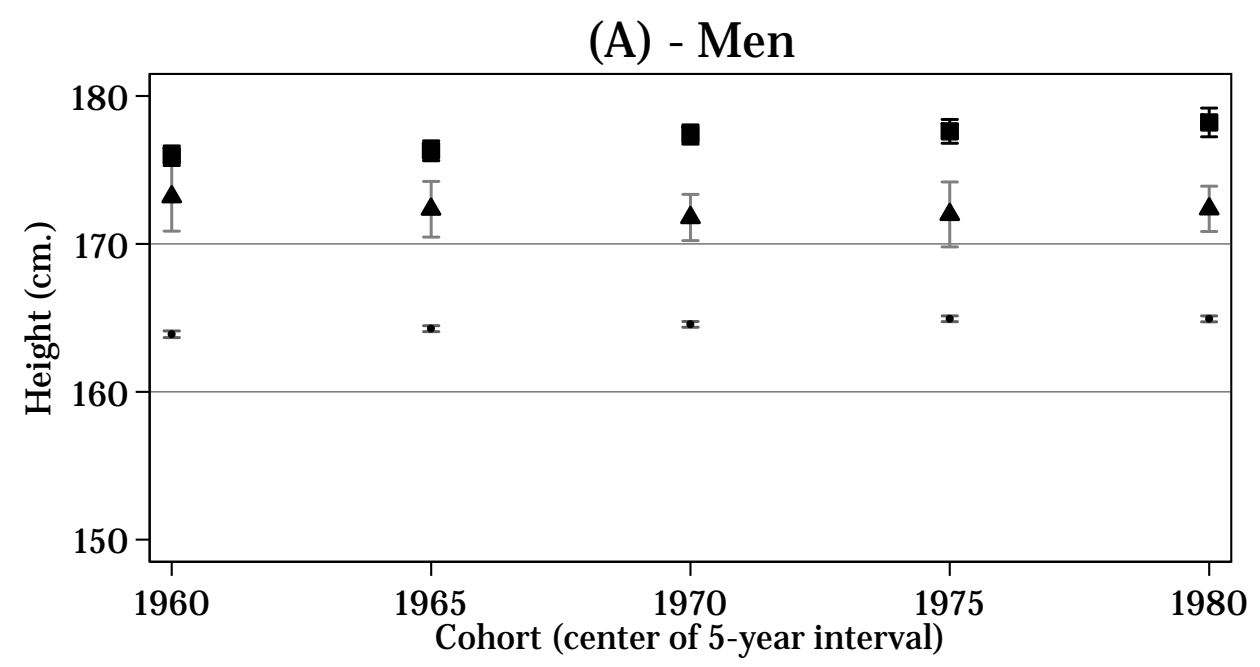

- India $\Delta$ England Indians $\quad$ England Whites

(B) - Women

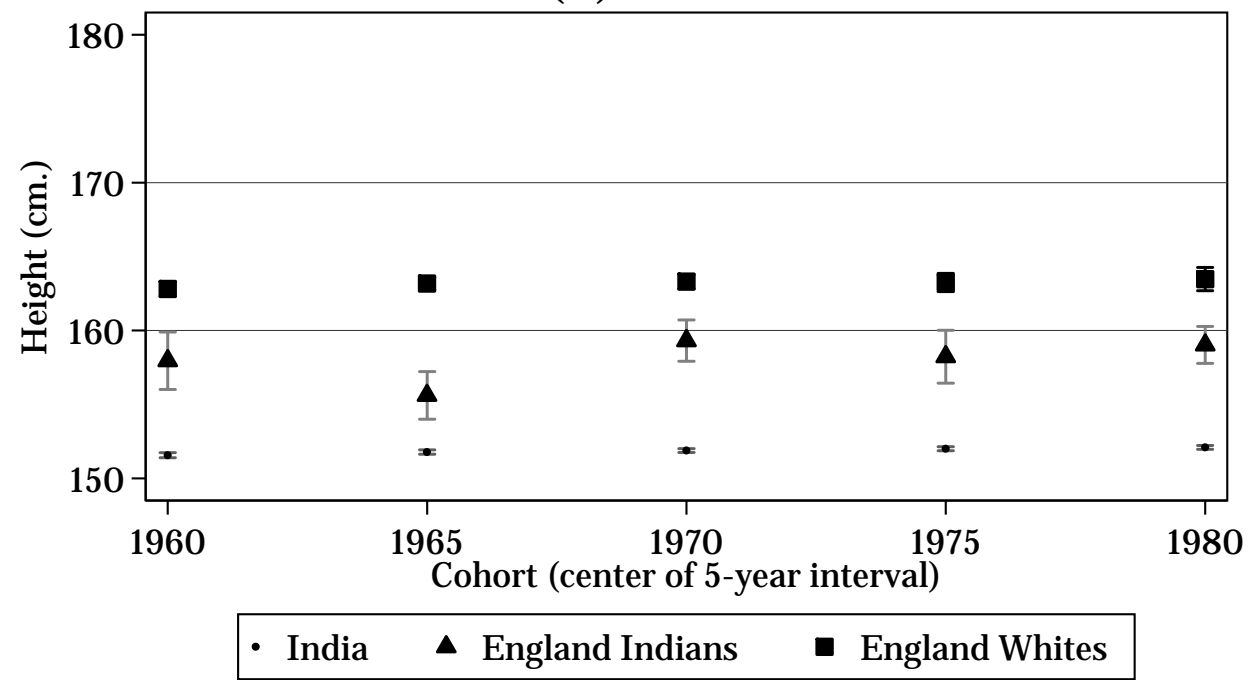

Figure A.11: Adult heights, excluding immigrants younger than 20 at time of migration

Source: Authors' estimations from NFHS-3 (2005-06), HSE 1999 and HSE 2004. Each point represents the average height of individuals, labeled as in the legend, whose reported year of birth was included in the 5 -year interval centered on the year labeled in the horizontal axis. Each point estimate is shown included within its $95 \%$ confidence interval. For men (panel A) sample sizes are 44,467 (NFHS-3), 363 (HSE, Indians) and 2,515 (HSE, Whites), while for women (panel B) they are respectively 80,346, 415 and 3,204. Estimates for ethnic Indians include only individuals who were older than 20 at the time of migration to Britain. All estimates use sample weights and confidence bands take into account the clustered design of each survey. 
Table A.10: Height Selection into Parenthood among Adults

\begin{tabular}{|c|c|c|c|c|}
\hline Sample & Subset & $\begin{array}{c}\text { Average } \\
\text { Height }\end{array}$ & S.E. & Obs. \\
\hline \multicolumn{5}{|l|}{ Men } \\
\hline Indians, NFHS-3 & All & 164.6 & 0.062 & 44467 \\
\hline Indians, NFHS-3 & Only parents & 164.4 & 0.086 & 14404 \\
\hline Ethnic Indians in England & All & 171.9 & 0.346 & 548 \\
\hline Ethnic Indians in England & Only parents & 170.9 & 0.874 & 94 \\
\hline Whites in England & All & 177.0 & 0.185 & 2515 \\
\hline Whites in England & Only parents & 176.8 & 0.423 & 339 \\
\hline \multicolumn{5}{|l|}{ Women } \\
\hline Indians, NFHS-3 & All & 151.9 & 0.047 & 80346 \\
\hline Indians, NFHS-3 & Only parents & 151.8 & 0.067 & 23736 \\
\hline Ethnic Indians in England & All & 157.2 & 0.318 & 662 \\
\hline Ethnic Indians in England & Only parents & 157.4 & 0.726 & 122 \\
\hline Whites in England & All & 163.2 & 0.129 & 3204 \\
\hline Whites in England & Only parents & 163.0 & 0.311 & 528 \\
\hline
\end{tabular}

Source: authors' estimations from NFHS-3, HSE 1999 and HSE 2004. Standard errors are clustered at the primary sampling unit level and all estimates use sampling weights. Estimates labeled 'All' are calculated using all available information from adults born between 1958 and 1982 (as in Figure 1), while those labeled 'Only Parents' include only the subset of these adults for whom the data set include non-missing information of the height of under five children.

Table A.11: Intergenerational Transmission of Height, HSE vs NFHS-3, by Age

\begin{tabular}{|c|c|c|c|c|c|c|}
\hline & (1) & $(2)$ & $(3)$ & $(4)$ & $(5)$ & $(6)$ \\
\hline & \multicolumn{3}{|c|}{ Girls } & \multicolumn{3}{|c|}{ Boys } \\
\hline & Age $=2$ & Age $=3$ & Age $=4$ & Age $=2$ & Age $=3$ & Age $=4$ \\
\hline England & $\begin{array}{l}0.0707 \\
(0.00898)\end{array}$ & $\begin{array}{l}0.0627 \\
(0.0147)\end{array}$ & $\begin{array}{l}0.0621 \\
(0.0141)\end{array}$ & $\begin{array}{l}0.0619 \\
(0.0113)\end{array}$ & $\begin{array}{l}0.0783 \\
(0.0113)\end{array}$ & $\begin{array}{l}0.0444 \\
(0.00956)\end{array}$ \\
\hline Log(Father's height) & $\begin{array}{l}0.295 \\
(0.0833)\end{array}$ & $\begin{array}{l}0.180 \\
(0.0651)\end{array}$ & $\begin{array}{l}0.337 \\
(0.0661)\end{array}$ & $\begin{array}{l}0.277 \\
(0.0566)\end{array}$ & $\begin{array}{l}0.193 \\
(0.0601)\end{array}$ & $\begin{array}{l}0.299 \\
(0.0624)\end{array}$ \\
\hline Log(Mother's height) & $\begin{array}{l}0.379 \\
(0.0731)\end{array}$ & $\begin{array}{l}0.472 \\
(0.0799)\end{array}$ & $\begin{array}{l}0.315 \\
(0.0661)\end{array}$ & $\begin{array}{l}0.252 \\
(0.0653)\end{array}$ & $\begin{array}{l}0.460 \\
(0.0625)\end{array}$ & $\begin{array}{l}0.343 \\
(0.0552)\end{array}$ \\
\hline Constant & $\begin{array}{l}1.001 \\
(0.455)\end{array}$ & $\begin{array}{l}1.212 \\
(0.449)\end{array}$ & $\begin{array}{l}1.266 \\
(0.423)\end{array}$ & $\begin{array}{l}1.746 \\
(0.390)\end{array}$ & $\begin{array}{l}1.216 \\
(0.414)\end{array}$ & $\begin{array}{l}1.328 \\
(0.413)\end{array}$ \\
\hline Observations & 2.014 & 2,018 & 1,852 & 2,156 & 2,175 & 2,049 \\
\hline $\mathrm{R}$-squared & 0.050 & 0.047 & 0.045 & 0.039 & 0.061 & 0.065 \\
\hline
\end{tabular}

Source: authors' estimations from NFHS-3, HSE 1999 and HSE 2004 (OLS regressions). HSE data include only children of Indian ethnicity. Standard errors (in parentheses) are clustered at the primary sampling unit level. The sample includes children age 2, 3 or 4 years. All coefficients are significant at the $1 \%$ level, except the intercept for 2 -year old girls, significant at the $5 \%$ level. 
Table A.12: Child Height: Average Changes by Age and Gender, IHDS-I vs. IHDS-II

(1)

\begin{tabular}{|c|c|c|c|c|}
\hline \multirow{2}{*}{$\begin{array}{c}\text { Age } \\
\text { (in years) }\end{array}$} & \multirow{2}{*}{$\begin{array}{l}\text { IHDS-I } \\
2005-06\end{array}$} & \multirow{2}{*}{$\begin{array}{c}\text { IHDS-II } \\
2011-12 \\
\end{array}$} & \multicolumn{2}{|c|}{ Difference } \\
\hline & & & $\mathrm{cms}$ & $\%$ \\
\hline \multicolumn{5}{|l|}{ (A) - Boys } \\
\hline & 58.4 & 58.9 & 0.526 & 0.009 \\
\hline 1 & 68.6 & 70.5 & 1.859 & 0.027 \\
\hline 2 & 78.0 & 79.4 & 1.416 & 0.018 \\
\hline 3 & 86.6 & 87.6 & 1.035 & 0.012 \\
\hline 4 & 94.2 & 95.0 & 0.771 & 0.008 \\
\hline 8 & 117.0 & 120.9 & 3.847 & 0.033 \\
\hline 9 & 121.9 & 124.9 & 2.997 & 0.025 \\
\hline 10 & 125.7 & 129.1 & 3.383 & 0.027 \\
\hline 11 & 131.3 & 134.8 & 3.543 & 0.027 \\
\hline \multicolumn{5}{|l|}{ (B) - Girls } \\
\hline 0 & 58.1 & 56.9 & -1.242 & -0.021 \\
\hline 1 & 68.1 & 69.6 & 1.544 & 0.023 \\
\hline 2 & 76.8 & 78.9 & 2.056 & 0.027 \\
\hline 3 & 85.3 & 86.9 & 1.545 & 0.018 \\
\hline 4 & 92.9 & 93.7 & 0.790 & 0.009 \\
\hline 8 & 117.0 & 119.0 & 2.026 & 0.017 \\
\hline 9 & 121.8 & 123.7 & 1.907 & 0.016 \\
\hline 10 & 125.8 & 128.5 & 2.709 & 0.022 \\
\hline 11 & 130.9 & 133.8 & 2.842 & 0.022 \\
\hline
\end{tabular}

Source: Authors' estimations from IHDS-I (2004-05) and IHDS-2 (2011-12). Figures in columns 1 and 2 represent the average height of children by age and gender (0-5 and 8-11 years old) in the survey specified in the header. The point estimates are the same used to construct the graphs in Figure A.6. We also report the differences in centimeters in column 3 and the relative differences in column 4. Panel A (boys) is based on 15,328 (IHDS-I) and 13,177 (IHDS-II) observations. Sample sizes for panel B (girls) are respectively 14,123 and 12,153. All estimates use sample weights. 